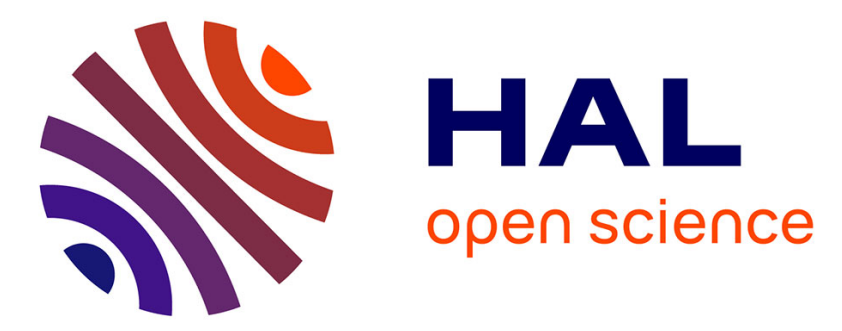

\title{
A Clusterized Energy Management with Linearized Losses in the Presence of Multiple Types of Distributed Generation
}

\author{
Rémy Rigo-Mariani, Keck Voon Ling, Jan Maciejowski
}

\section{- To cite this version:}

Rémy Rigo-Mariani, Keck Voon Ling, Jan Maciejowski. A Clusterized Energy Management with Linearized Losses in the Presence of Multiple Types of Distributed Generation. International Journal of Electrical Power \& Energy Systems, 2019, 113, pp.9-22. hal-03016675

\section{HAL Id: hal-03016675 \\ https://hal.science/hal-03016675}

Submitted on 20 Nov 2020

HAL is a multi-disciplinary open access archive for the deposit and dissemination of scientific research documents, whether they are published or not. The documents may come from teaching and research institutions in France or abroad, or from public or private research centers.
L'archive ouverte pluridisciplinaire HAL, est destinée au dépôt et à la diffusion de documents scientifiques de niveau recherche, publiés ou non, émanant des établissements d'enseignement et de recherche français ou étrangers, des laboratoires publics ou privés. 


\title{
A Clusterized Energy Management with Linearized Losses in the Presence of Multiple Types of Distributed Generation
}

\author{
Rémy Rigo-Mariani, Keck Voon Ling, Jan Maciejowski \\ Cambridge Centre for Advanced Research and Education in Singapore
}

\begin{abstract}
This paper presents an optimal management (OM) strategy for distributed generation (DG) planning whose objective is the $\mathrm{CO}_{2}$ reduction for the power generation on the Jurong Island in Singapore. Different DG resources are investigated with solar generation, energy storage, small gas turbine as well as controllable loads in addition to the centralized generation already in site. Each of those resource is modeled in an optimal scheduling method that allow to test a great number of different DG configurations (i.e. type/size/site). The paper mainly focuses on the OM implementation that would allow avoiding prohibitive computational times. At first it is achieved thanks to a linearization of the line losses and a modified DC power flow. When simulating the system over a representative day. Then a generic clustering method is developed as well as a sequential optimal management (S-OM) with the zonal and nodal models is implemented. Different validation tests are performed as well as sets of simulation with different DG configurations. The optimal DG planning procedure will be part of further developments.
\end{abstract}

Index Terms-Distributed generation, MILP, $\mathrm{CO}_{2}$ emissions, energy storage, controllable load, network partitioning.

\section{INTRODUCTION}

The work presented in this paper focuses on reducing carbon emissions due to the power generation on Jurong Island in Singapore. That island hosts around $40 \%$ percent of the total generation capacity in Singapore with thirteen identified Combined Cycle Gas Turbine (CCGT) units aggregated in four power plants [1][2]. A great part of the generated energy is consumed on the island by refineries, oil storage facilities and other petrochemical activities while the surplus is exported to the Singaporean mainland. The integration of distributed generation (DG) to the existing system is investigated as a way to reduce the emissions compared to the current base scenario in which only the centralized generation (i.e. the four power plants) is considered. The advantage of DG assets is to bring more diverse resources as well as more flexibility with various additional benefits such as loss reduction, improved reliability or the deferment of grid investments [3] [4]. In such a framework typical DG planning problems aim at finding the best types, sizes and allocations of the assets that minimize the considered objective function (i.e. $\mathrm{CO}_{2}$ emissions for a representative day here) [5]. The main concern when facing such problems is to avoid the computational burden while estimating the performances of many different DG configurations. The complexity of these DG 
planning studies can be disaggregated in three parts. Firstly, the numbers and types of the considered distributed resources directly impacts the amount of possible configurations to test. Simplest case studies investigate the placement of single generic PQ units with exhaustive search or analytical approaches [6] [7]. More complex problems consider multiple generic PQ units [8] or multiple types of resources with both renewable and storage units [9] [10]. This paper investigates different DG technologies, including photovoltaic generation (PV), energy storage (ST) and distributed CCGT units (DU). The presence of controllable loads (CL) is also studied which is not commonly done in the literature. The second degree of complexity for DG planning studies comes from the size of the modeled power system which obviously increases the number of possible DG configurations (i.e. types/sizes/sties). Typical systems encountered literature display a wide range for their number of buses from less than 10 [11] to over 100 [12] while the Jurong Island system is modeled here with a little more than 200 nodes. Thirdly, the difficulty to solve those planning problems is enhanced when longer time horizons are considered to compute the objective function. Indeed, many studies only refers to a single snapshot power flow with one load level, to compute the cost, losses or reliability index corresponding to every DG configuration estimated [11] [13] [14]. Some works run simulations over a whole year with successive independent AC optimal power flow (AC OPF), as in [15] [16]. However, when storage units are considered, as it the case in this paper, the introduction of time related constraints (e.g. the state of charge computation) implies that the whole time horizon needs to be represented in the optimization problems and successive AC OPF cannot be applied. Thus, authors often refer to simplified DC OPF with the extensive use of linearized formulations in order to avoid prohibitive computation times [17] [18] (See table in Appendix A for a summary of the reviewed studies).
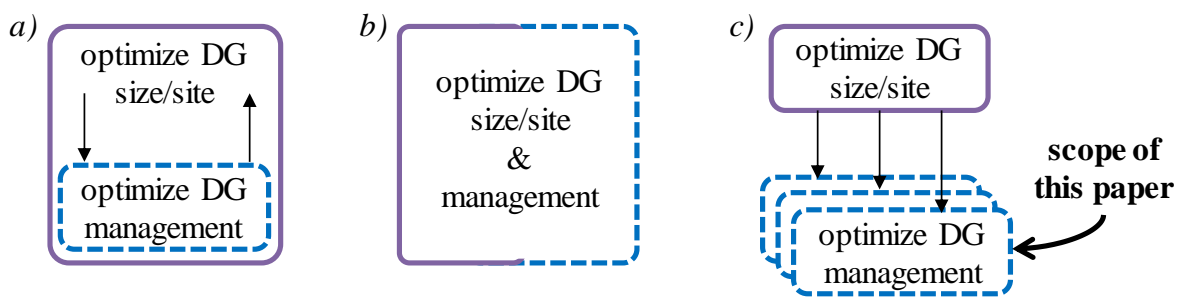

Figure 1: Coupling between design and management loops $-a$ ) integrated $-b$ ) all in one $-c$ ) iterative

With time series profiles considered, DG planning studies can be seen as systematic optimization problems The goal is to find the best configuration for the DG assets (i.e. design loop) whose operation over a given time horizon (i.e. management loop) corresponds to the best values of the objective. Several approaches are identified in the literature, with different couplings between the management and design loops [19]. Bi-level optimization is often used where the DG sizes/sites are part of an outer loop problem while the management is solved in an inner loop (Figure 1a). Typically, the design variables generated in the outer level are used as input parameters for the inner level with two integrated optimization problems. Such an approach is presented 
in [9] [20] [21] with the DG management over a day performed by dynamic programming or successive AC OPF while genetic algorithms try to find the best design in terms of DG sites/sizes. A second class of works refer to "all in one" approaches where both design and management variables are part of a single optimization problem (Figure 1b), usually using LP or MILP formulation [17] [18]. However, the convergence of the global problem might not be ensured in a reasonable time. The architecture considered in this paper corresponds to a classical iterative method which consists in several estimations of the management loop for different configurations and attempts to improve the design (Figure 1c). [10] [22] use such a method with successive AC OPF for the management strategy while different designed are generated with Monte Carlo simulations or an analytical approach.

This paper mainly focuses on the implementation of the DG management strategy within an iterative architecture for DG planning. Also note that the optimal operation of the assets is jointly considered with the schedule of the centralized resources on sites. DG integration will change the generation mix of the Jurong Island along with more flexibility provided by storage units and the ability to perform load control. Thus the management loop will be implemented in the form of a typical unit commitment problem (UC) with the existing power plants and the addition of DG resources whose connection buses and sizes are input parameters. Note that today the generations companies in Jurong Island bid in the national Singaporean market before the Power System Operator runs the UC [2]. In this work, the assumption is made that all the power plants and DG assets are centrally owned and managed by a vertical entity that could be the already existing "Jurong Island Community" for instance. A specific attention is paid to the computational time that has to be small enough in order to test a great number of DG configurations (i.e. types/sizes/sites). It is achieved here in two steps that are the main contributions of the proposed approach. Firstly, losses within the lines are linearized using a modified DC OPF. Unlike conventional iterative approaches [23] [24], the method developed here is faster and reference independent. It lies on the linear coefficients extracted from preliminary sets of simulations with several run of AC OPF and it is denoted as OM (Optimal Managemen). Secondly, a clustering approach allows fast computational times while dealing with a reduced number of variables. In DG planning studies, clustering methods are often used to reduce the input information and the long time horizons are then represented by a limited number of representative time steps [15]. Other efficient clustering approaches consist in grouping the generations assets by type of resources [25] or by units displaying similar characteristics [26]. In this paper the clustering procedure is considered to perform a network partitioning based its topology while computing the "electrical distances". In particular, that zonal decomposition lies in a partitioning method that automatically ensures the cluster connectedness to improve the convergence of the clustering method. Finally, a sequential management procedure with zonal and nodal representations (denoted as S-OM) is implemented in order to ensure the 
convergence of the management strategy in a faster computational time. It lies on successive runs of the previously OM within each cluster and for the overall system zonal representation.

The rest of the paper is organized as follow. Section 2 presents the management strategy run over a representative day. The mathematical formulation of the OMLL method is described with a particular attention paid to the power plant operation constraints for the centralized generation. The models for the different types of DG assets are detailed as well as the modified DC OPF constraints that integrates the proposed approximations for the line losses. Then Section 3 introduces the partitioning algorithm that performs the network clustering and the sequential zonal/nodal algorithm is presented. Finally, Section 4 gives a set of different results that allows to validated the proposed approaches (OM and S-OM) as well as the developed models. Different DG configurations added to the existing centralized assets are investigated. However, it is important to remind that the paper focuses on the management loop only (Figure 1c). The design strategy that would aim at estimating the best configurations will be part of further works.

\section{OPTIMAL MANAGEMENT WITH LOSS LINEARIZATION}

\section{A. Jurong Island Power System}

As already mentioned the case study is the transmission grid in the Jurong Island of Singapore. Figure $2 a$ displays the corresponding model with the topology of the high voltage lines/buses as well as the position of the four existing power plants. Note that the 208 buses/219 branches model was built based on assumptions and does not necessarily represent the real topology. In particular, line impedances are computed from cables manufacturers datasheets and the geographic coordinates of the identified load points. Lines ratings are estimated based on the load at each node with four types of consumers are identified: refineries, oil storage, chemical plants and offices. The voltage connection of each of those consumers depends on their rated power following the rules of connection in Singapore. The centralized generation on site consists in thirteen CCGT units displaying five different technologies (denoted from A to E). Those thirteen units are among the four power plants as follow: Keppel (KPL): 2 units type A and two units type B - Pacific Light Power (PLP): 2 units type C - Sembcorp (SMB): 1 unit type A and 2 units type D - Seraya (SRY): 2 units type C and 2 units type E. Previous works focused on the modeling of the $\mathrm{CO}_{2}$ emissions of the CCGT technologies based on their operating points and efficiency (ranging from 53\% to 62\%) [1]. Their nominal operating points and part load operations were simulated to finally compute their specific $\mathrm{CO}_{2}$ emissions $(S C E$ in $\mathrm{kg} / \mathrm{kWh}$ ) (Figure 2a). An environmental unit was developed to consider those "carbon costs" in a $\mathrm{CO}_{2}$ minimization while supplying a representative load profile. The optimal management developed in this paper lies on the same strategy with more 
complexity coming from the addition of different types of DG assets to the existing generation portfolio. Figure $2 b$ shows the a the daily deterministic load that have to be supplied with a 30 minute time step while aggregating the load for all the four types of consumers.
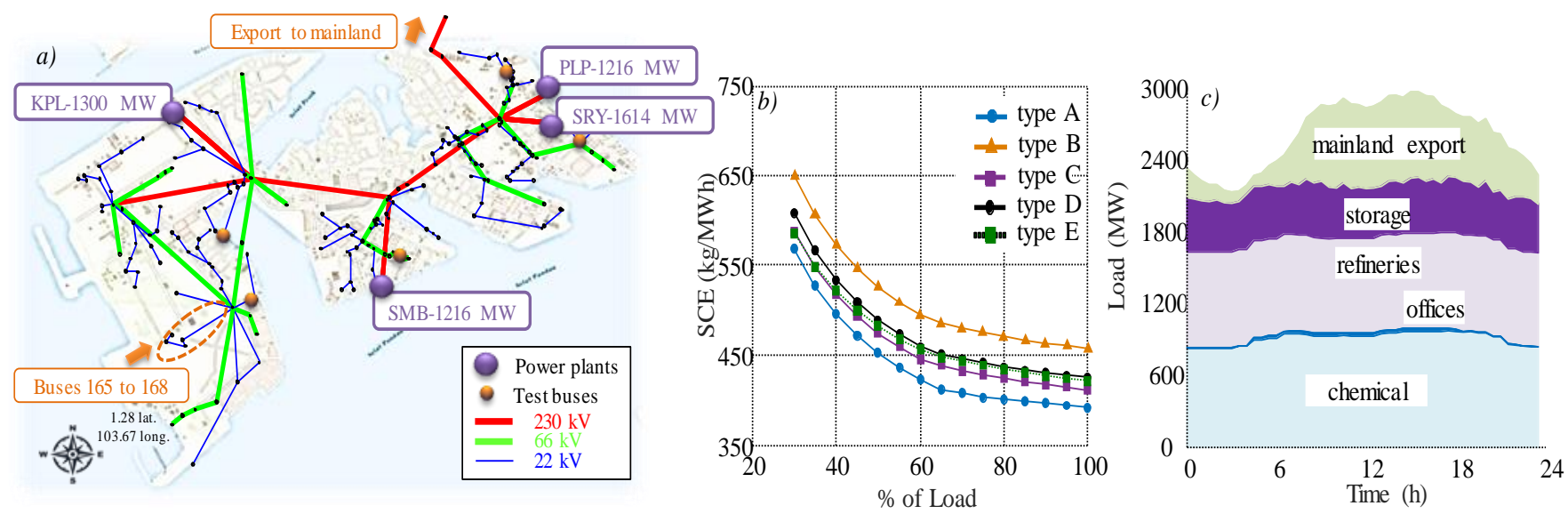

Figure 2: Jurong Island Power System - a) Grid topology - b) $\mathrm{CO}_{2}$ emissions of centralized CCGT technologies $-c$ ) aggregated load profiles

\section{B. Environmental Unit Commitment Objective}

As already mentioned the management strategy is implemented in the form of a typical unit commitment (UC) with both centralized power plants and distributed resources. A typical MILP formulation is consider here with the objective to minimize those emissions while fulfilling a set of traditional constraints such as minimum up/down times and considering startup and shut-down carbon costs [27]. It is important to note that the units contributing to the emissions are the centralized generators in existing power plants (index CG) as well as the smaller distributed units (index DU) that are considered in the DG planning framework. Mathematically the formulation is the same for those two types of generators. The distinction is made as the centralized assets will remain the same (size/site) while the smaller units portfolio will change depending on the different DG configurations that might be investigated. Thus equation (1) allows to compute the total $\mathrm{CO}_{2}$ emissions for both centralized and distributed thermal units located at the system buses (bus set B) and along the simulated day (time set $T$ ) discretized at an half hourly time step $\Delta t$. The computation considers the on/off $\left(u_{b, t}^{C G}, u_{b, t}^{D U}\right)$ and startup $\left(v_{b, t}^{C G}, v_{b, t}^{D U}\right)$ conditions of the units at bus $b$ at time $t$ as well as the corresponding base "carbon costs" $\left(C 0_{b}^{C G}, C 0_{b}^{D U}\right)$ and startup emissions $\left(S U_{b}^{C G}, S U_{b}^{D U}\right)$. The piecewise linearization is run along $C$, the set of linear blocks, in which the generated power $\left(p_{c, b, t}^{C G}, p_{c, b, t}^{D U}\right)$ is attach to a cost $\left(a_{c, b}^{C G}, a_{c, b}^{D U}\right)$.

$o b j=\sum_{t \in T} \sum_{b \in B}\left(\left(C 0_{b}^{C G} \times u_{b, t}^{C G}+\sum_{c \in C} a_{c, b}^{C G} \times p_{c, b, t}^{C G}\right) \times \Delta t+S U_{b}^{C G} \times v_{b, t}^{C G}+\left(C 0_{b}^{D U} \times u_{b, t}^{D U}+\sum_{c \in C} a_{c, b}^{D U} \times p_{c, b, t}^{D U}\right) \times \Delta t+S U_{b}^{D U} \times v_{b, t}^{D U}\right)$ 
Table 1: List of the used symbols in the OMLL

\begin{tabular}{|c|c|c|}
\hline \multicolumn{3}{|l|}{ Sets : } \\
\hline$b \in B$ & set of buses & - \\
\hline$t \in T$ & set of time steps & - \\
\hline$c \in C$ & set of linear blocks for the CCGT carbon emissions & - \\
\hline$l \in L$ & set of lines & - \\
\hline$w \in W$ & set of linear blocks for line losses estimation & - \\
\hline$n \in N$ & set of grid cluster (with buses and lines) & - \\
\hline$b_{n} \in B_{n}$ & set of equivalent buses in zonal model & - \\
\hline$l_{n}^{n} \in L_{n}^{n}$ & set of lines in in zonal model (subset of $L$ ) & - \\
\hline \multicolumn{3}{|l|}{ Variables : } \\
\hline$u_{b, t}^{C G}, u_{b, t}^{D U}$ & on/off status of CCGT unit at bus $b$ at time $t\{0,1\}$ & - \\
\hline$v_{b, t}^{C G}, v_{b, t}^{D U}$ & startup of CCGT unit at bus $b$ at time $t\{0,1\}$ & - \\
\hline$p_{c, b, t}^{C G}, p_{c, b, t}^{D U}$ & CCGT unit power at bus $b$ operating in block $c$ at time $t$ & MW \\
\hline$P_{b, t}^{C G}, P_{b, t}^{D U}$ & power output of CCGT unit at bus $b$ at time $t$ & \\
\hline$P_{b, t}^{C G\{k\}}$ & power output of a unit $k$ in power plant at bus $b$ at time $t$ & MW \\
\hline$\Delta u_{b, t}^{C G\{k\}+}, \Delta u_{b, t}^{C G\{k\}-}$ & up/down ramp of unit $k$ in power plant at bus $b$ at time $t\{0,1\}$ & - \\
\hline$F_{l, t}^{+}, F_{l, t}^{-}$ & positive/negative power flows in line $l$ at time $t$ & MW \\
\hline$\delta F_{l, t}^{+}, \delta F_{l, t}^{-}$ & positive/negative power flows in line $l$ at time $t$ & MW \\
\hline$f_{W, l, t}^{+}, f_{W, l, t}^{-}$ & positive/negative power flows in block $w$ of line $l$ at time $t$ & MW \\
\hline$\theta_{b, t}$ & voltage angle at bus $b$ at time $t$ & p.u. \\
\hline$P_{b, l}^{\Sigma}$ & power balance of at bus $b$ at time $t$ & MW \\
\hline$\delta P_{b, t}^{P V-}$ & curtailed PV generation at bus $b$ at time $t$ & MW \\
\hline$P_{b, t}^{S T-}, P_{b, t}^{S T+}$ & charge/discharge powers of storage at bus $b$ at time $t$ & MW \\
\hline$S O C^{b, t}$ & state of charge of distributed storage at bus $b$ at time $t$ & $\%$ \\
\hline$u_{n, t}^{\sum C L-}, u_{n, t}^{\sum C L+}$ & control for decrease/increase of cluster $n$ at time $t\{0,1\}$ & - \\
\hline \multicolumn{3}{|l|}{ Parameters : } \\
\hline$C O_{b}^{C G}, C 0_{b}^{D U}$ & base $\mathrm{CO}_{2}$ emissions of CCGT unit at bus $b$ & tons \\
\hline$S U_{b}^{C G}, S U_{b}^{D U}$ & startup $\mathrm{CO}_{2}$ emissions of CCGT unit at bus $b$ & tons \\
\hline$a_{c, b}^{C G}, a_{c, b}^{D U}$ & ooperating $\mathrm{CO}_{2}$ emissions of units bus $b$ operating in block $c$ & tons/MWh \\
\hline$p_{c, b}^{C G \max }, p_{c, b}^{D U \max }$ & upper bound of CCGT unit power at bus $b$ operating in block $c$ & MW \\
\hline$P_{b}^{C G \min }, P_{b}^{C G \max }$ & $\min / \max$ output power of centralized CCGT unit at bus $b$ & MW \\
\hline$P_{b}^{D U \min }, P_{b}^{D U \max }$ & $\min / \max$ output power of distributed CCGT unit at bus $b$ & MW \\
\hline$\Delta P_{\max }^{C G}$ & maximum ramp value for the centralized CCGT units & MW \\
\hline$f_{w, l}^{\max }$ & maximum power flow in block $w$ of line $l$ at time $t$ & MW \\
\hline$F_{l}^{\max }$ & maximum flow in line $l$ & MW \\
\hline$\alpha_{w, l}^{\delta F}$ & loss factor in block $w$ of line $l$ & - \\
\hline $\mathbf{B}^{\text {bus }}$ & $\mathrm{B} \times \mathrm{B}$ bus admittance matrix & p.u. \\
\hline$P_{b, t}^{P V}$ & available PV generation at bus $b$ at time $t$ & MW \\
\hline$P_{b}^{S T \max }, E_{b}^{S T \max }$ & rated power/energy for storage at bus $b$ & MW/MWh \\
\hline$\eta^{S T}$ & generic storage power efficiency (typically 0.975 ) & - \\
\hline$\Delta P_{n}^{\Sigma C L}, T_{n}^{\Sigma C L}$ & power magnitude and duration of control phase of cluster $n$ & $\mathrm{MW} / \mathrm{h}$ \\
\hline$\Delta p_{b \in n}^{C L}$ & power magnitude for CL at bus $b$ in cluster $n$ & MW \\
\hline$P_{b, t}^{L}$ & load at bus $b$ at time $t$ & MW \\
\hline
\end{tabular}

Carbon costs linearization requires sets of typical variable and constraints [28] in order to compute the output power of the CCGT units $\left(P_{b, t}^{C G}, P_{b, t}^{D U}\right)$ based on their on/off status, minimum output power $\left(P_{b}^{C G m i n}, P_{b}^{D U m i n}\right)$ and their operation within each linear blocks $c$ (2). The contribution in each block is subject to upper bounds $\left(p_{c, b}^{C G \max }, p_{c, b}^{D U m a x}\right)((3))$ and constraint (4) finally ensures that each units operates within its acceptable range if it is on. Conventional ramping limits and up/down-times constraints 
do not appear here for the sake of simplicity. A full list of the symbols used in the optimal management strategy is given in Table 1.

$$
\begin{aligned}
& P_{b, t}^{C G}=P_{b}^{C G \min } \times u_{b, t}^{C G}+\sum_{c \in C} p_{c, b, t}^{C G} \quad \text { and } \quad P_{b, t}^{D U}=P_{b}^{D U m i n} \times u_{b, t}^{D U}+\sum_{c \in C} p_{c, b, t}^{D U} \\
& 0 \leq p_{c, b, t}^{C G} \leq p_{c, b}^{C G \max } \quad \text { and } \quad 0 \leq p_{c, b, t}^{D U} \leq p_{c, b}^{D U m a x} \\
& P_{b}^{C G \min } \times u_{b, t}^{C G} \leq P_{b, t}^{C G} \leq P_{b}^{C G \max } \times u_{b, t}^{C G} \quad \text { and } \quad P_{b}^{D U \min } \times u_{b, t}^{D U} \leq P_{b, t}^{D U} \leq P_{b}^{D U m a x} \times u_{b, t}^{D U}
\end{aligned}
$$

\section{Centralized Power Plants OperationConstraints}

Unlike most UC studies in the literature, the different CCGT units are here aggregated among distinct power plants that display several generators with the same technology (i.e. the same parameters). All the generators $k$ within a same power plant being connected to the same bus, the optimization may lead to unrealistic cases: two units $k$ and $k$ ' of the same technology in a same plant opposite deviations (up/down ramps) between two successive time steps while the sum of their output power remains constant. With the considered mathematical formulation, such "distorted profiles" would correspond to the same emissions as a case where units $k$ and $k^{\prime}$ would generate a constant power. Thus additional variables and constraints are introduced for the centralized generation in order to obtain more realistic operation of the power plants [29]. Binary variables $\Delta u_{b, t}^{C G\{k\}+}$ and $\Delta u_{b, t}^{C G\{k\}-}$ allow the identification of the up/down ramp direction of each concerned units $k$ at bus $b$ at time $t$. Those ramp direction are computed with constraint (5) with $\Delta u_{\max }^{C G}$ being the maximum expected power deviation (set to a high value) and $P_{b, t}^{C G\{k\}}$ the output power of the power plant unit $\mathrm{k}$ at bus $\mathrm{b}$ at time $\mathrm{t}$. That power has minimum and maximum value and is subject to conventional operating constraints related to the piecewise linearization of the carbon costs. Logical constraint (6) ensures that the deviations can be either positive or negative. Finally (7)-(8) allow to give priority (arbitrarily) to unit $k^{\prime}$ over another unit $k^{\prime \prime}$ if $k^{\prime}$ and $k^{\prime \prime}$ display the same technology within the same power plant. Note that only one of the two constraints in (8) is necessary, the other being implicitly fulfilled with (6).

$$
\begin{aligned}
& -\Delta P_{\max }^{C G} \times \Delta u_{b, t}^{C G\{k\}-} \leq P_{b, t}^{C G\{k\}}-P_{b, t-1}^{C G\{k\}} \leq \Delta P_{\max }^{C G} \times \Delta u_{b, t}^{C G\{k\}+} \\
& \Delta u_{b, t}^{C G\{k\}-}+\Delta u_{b, t}^{C G\{k\}+} \leq 1 \\
& P_{b, t}^{C G\left\{k^{\prime}\right\}} \geq P_{b, t}^{C G\left\{k^{\prime \prime}\right\}} \\
& \Delta u_{b, t}^{C G\left\{k^{\prime}\right\}-}+\Delta u_{b, t}^{C G\left\{k^{\prime \prime}\right\}+} \leq 1 \text { or } \Delta u_{b, t}^{C G\left\{k^{\prime}\right\}+}+\Delta u_{b, t}^{C G\left\{k^{\prime \prime}\right\}-} \leq 1
\end{aligned}
$$




\section{Modified DC OPF for Line Losses Linearization}

This subsection describes the introduction of the line losses estimation in the developed optimal management. That estimation is necessary if the impact of different locations of the resources is investigated. AC power flow equations provide an exact computation of those losses when DG planning studies only considers single load level. However, a DC power flow should be considered here to avoid prohibitive computational times while optimizing over a daily time horizon. Conventional loss estimation in DC power flow lies in the computation of the marginal loss factor and generation shift factor matrixes [30]. The approaches require the integration of an offset that represent an initial guess of the total system loss which is not necessary available. Iterative approaches such as [24] allow to overcome that problem but might unnecessary increase the computational time with several runs needed. The Jump and Shift iterative method [23] will be further considered as a base case to validate the method developed in this paper. Thar method lies in a modified DC power flow that discriminates the flow directions $F_{l, t}^{+}$and $F_{l, t}^{-}$in line $l$ at time $t$ before performing a linearization of the corresponding losses $\delta F_{l, t}^{+}$and $\delta F_{l, t}^{-}$. A preprocessing step is needed in which several AC OPF are run with random load levels and using a dedicated power flow package (Matpower here). A piecewise linearization of $\mathrm{W}$ blocks $(W=1$ and $\mathrm{W}=2)$ is then performed for each lines using a regular least square method (Figure 3).

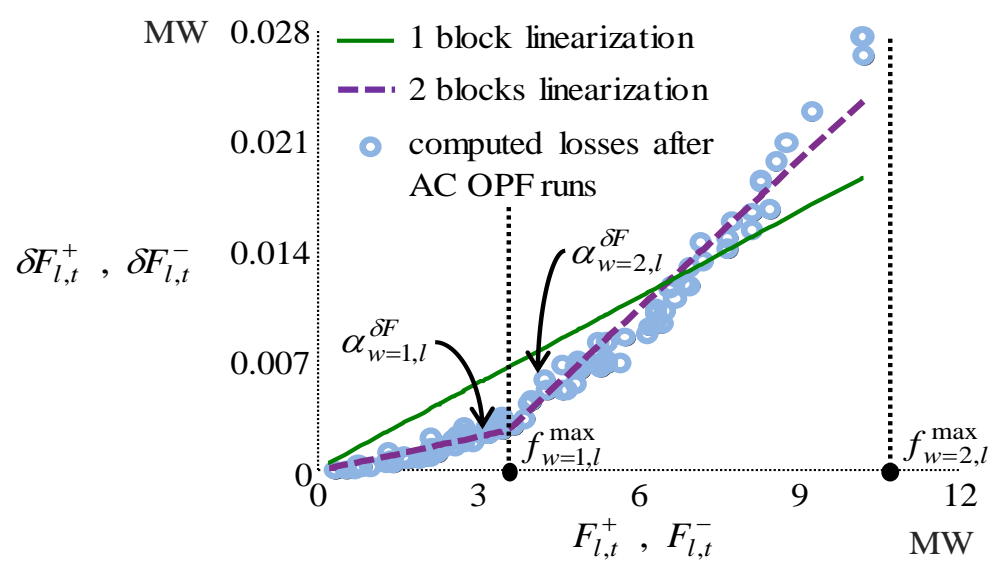

Figure 3: Line Loss Linearization

Similarly to the linearization of the $\mathrm{CO} 2$ emissions new sets of variables and constraints allow the loss estimation with

$f_{w, l, t}^{+}, f_{w, l, t}^{-}$the positive/negative instantaneous line flow in block $w$ and their corresponding upper bounds $f_{w, l}^{\max }$. Similarly to the piecewise linearization of the carbon cost function, $W$ intervals are defined to compute the power flowing thought the branch ((9)). Equation (10) implicitly allows the avoidance of line congestion $\left(0 \leq F_{l, t}^{+}, F_{l, t}^{-} \leq F_{l}^{\max }\right)$. Note that for transformers, only unidirectional flows are possible meaning that either the positive or the negative flow has to remain null depending on the 
transformer definition (i.e. start/end buses). Finally, line losses are computed following (11) with the slope coefficients $\alpha_{w, l}^{\delta F}$ estimated in the preprocessing phase for each block $w$ of every line $l$.

$$
\begin{aligned}
& F_{l, t}^{+}=\sum_{w \in W} f_{w, l, t}^{+} \text {and } F_{l, t}^{-}=\sum_{w \in W} f_{w, l, t}^{-} \\
& 0 \leq f_{w, l, t}^{+} \leq f_{w, l}^{\max } \text { and } 0 \leq f_{w, l, t}^{-} \leq f_{w, l}^{\max } \\
& \delta F_{l, t}^{+}=\sum_{w \in W} \alpha_{w, l}^{\delta F} \times f_{w, l, t}^{+} \text {and } \delta F_{l, t}^{-}=\sum_{w \in W} \alpha_{w, l}^{\delta F} \times f_{w, l, t}^{-}
\end{aligned}
$$

That piecewise linearization is integrated in a conventional DCPF formulation [31] where line flows are computed with the bus admittance matrix $\mathbf{B}^{\text {bus }}$ and the bus instantaneous voltage angles $\theta_{b, t}(12)$. Finally, the power balance at each bus is computed according to (13) as the contribution of the in the branches arriving at the bus or departing from it. Noted that similarly to the method developed in [30] the losses within a line are equally distributed at the start and end buses as additional loads.

$$
\begin{aligned}
& \left\{\begin{array}{l}
F_{l, t}^{+}-F_{l, t}^{-}=\mathbf{B}_{\mathbf{b}^{\prime} \mathbf{b}^{\prime \prime}}^{\text {bus }} \times\left(\theta_{b^{\prime}, t}-\theta_{b^{\prime \prime}, t}\right) \text { with line } l \text { defined from } b^{\prime} \text { to } b^{\prime \prime} \\
\theta_{1, t}=0 \quad \forall t \in T \quad(\text { slack bus } b=1)
\end{array}\right. \\
& P_{b, t}^{\Sigma}=\sum_{l \in \text { lines from } b}\left(F_{l, t}^{+}+\frac{\delta F_{l, t}^{+}}{2}\right)-\left(F_{l, t}^{-}-\frac{\delta F_{l, t}^{-}}{2}\right)-\sum_{l \in \text { lines to } b}\left(F_{l, t}^{+}-\frac{\delta F_{l, t}^{+}}{2}\right)-\left(F_{l, t}^{-}+\frac{\delta F_{l, t}^{-}}{2}\right)
\end{aligned}
$$

\section{E. Integration of DG Resources}

\section{1) Conventional DG assets}

This section introduces the modeling for the different DG assets in the developed optimal management with linearized losses (OMLL). Firstly, PV distributed generation at bus $b$ and time $t P_{b, t}^{P V}$ is considered with different sizes of installations simulated using a normalized profile for a $1 \mathrm{MWc}$ plant in Singapore that was generated with the PVwatts tool from the National Renewable Energy Laboratory [32]. The management strategy considers the possibility to curtailed the PV generation with the variable $\delta P_{b, t}^{P V-}$ (14) in order to avoid potential line congestion is case of oversized installation [33]. The second type of considered DG resources corresponds to distributed generic energy storage (ST) devices. A typical linear formulation is used while discriminating the charge $\left(P_{b, t}^{S T-}\right)$ and discharge $\left(P_{b, t}^{S T+}\right)$ powers for the units at bus $b$ at time $t$. A power efficiency $\eta^{S T}=97.5 \%$ is introduced to compute the state of charge $S O C_{b, t}$ following (15) with the rated energy $E_{b}^{S T m a x}$ and the initial charge level $S O C_{b, t=0}$ (typically $50 \%$ ) [17]. The set of constraints ensures to fulfill the power/energy limitations and enforces the storage devices to come back at their initial SOC at the end of the simulated day. The last type of conventional DG resources that is considered correspond to small CCGT. The operating parameters of those distributed units (DU) derive from the technology A 
with value scale down for smaller rated power. The operating constraints of those assets are similar to the ones implemented for the centralized thermal units and have already been discussed in section 2.A.

$0 \leq \delta P_{b, t}^{P V-} \leq P_{b, t}^{P V}$

$S O C_{b, t}=S O C_{b, t=0}-\frac{100 \times \Delta t}{E_{b}^{S T m a x}} \times \sum_{i=1}^{t}\left(\frac{P_{b, i}^{S T+}}{\eta^{S T}}-\eta^{S T} \times P_{b, i}^{S T-}\right)$

$0 \leq P_{b, t}^{S T-}, P_{b, t}^{S T+} \leq P_{b}^{S T m a x} \quad, \quad 0 \leq S O C_{b, t} \leq 100 \quad, \quad S O C_{b, t=T}=S O C_{b, t=0}$

\section{2) Controlable loads}

This paper considers load controllability (CL) as a potential DG resource. Many strategies are investigated in the literature when dealing with load control ranging from highly centralized demand response methods to the fully distributed transactive energy framework [Kok 16]. In this study a centralized control is implemented as the assumption is made that a vertical utility (Jurong Island Community here) owns and operates all the assets on site. In particular, it implies that the customers on site agrees to change their consumption pattern accordingly to central controls which might lead to some privacy issues and be challenging when heavy industrial customers are concerned. Incentives policies should then be considered but it is not in the scope of this paper. Distributed energy storage already provides an example of full continuous flexibility with controllable charge/discharge powers. Here the load control strategy relies on discrete load increments or decrements that would correspond to the time shifting of chemical processing by the considered consumers. The idea is to provide a different type of flexibility. Also, in order to better manage the complexity, loads are aggregated within $N$ distinct clusters using a network partitioning strategy that will be discussed in the next section. The actual load control will then be applied to clusters and not individual customers. Each of those cluster $n$ agrees in advance upon a global load level $\Delta P_{n}^{\Sigma C L}$ and duration $T_{n}^{\Sigma C L}$ for the control phase. If a power decrease $\left(u_{n, t}^{\Sigma C L-}\right)$ or increase $\left(u_{n, t}^{\Sigma C L+}\right)$ for the cluster $n$ is triggered at time $t$ (i.e. variables set to 1 by the management), all the loads in cluster $n$ (i.e. $b \in n$ ) will adapt their profiles according to a predefined individual level $\Delta p_{b}^{C L}$ as presented in Figure 4 . Equation (17) ensures that power uprate and derate within each cluster do not occur simultaneously while (18) allows controlling the shift phase duration with only one load shifting occurring each day ((19)).

$$
\begin{aligned}
& u_{n, t}^{\Sigma C L+}+u_{n, t}^{\Sigma C L-} \leq 1 \\
& u_{n, t}^{\Sigma C L+}-u_{n, t-1}^{\Sigma C L+} \leq \frac{1}{T_{n}^{\Sigma C L}} \times \sum_{i=t}^{t+T_{n}^{\Sigma C L}-1} u_{n, i}^{\Sigma C L+} \quad \text { and } \quad u_{n, t}^{\Sigma C L-}-u_{n, t-1}^{\Sigma C L-} \leq \frac{1}{T_{n}^{\Sigma C L}} \times \sum_{i=t}^{t+T_{n}^{\Sigma C L}-1} u_{n, i}^{\Sigma C L-} \\
& \sum_{t \in T} u_{n, t}^{\Sigma C L+}=\sum_{t \in T} u_{n, t}^{\Sigma C L-}=T_{n}^{\Sigma C L}
\end{aligned}
$$




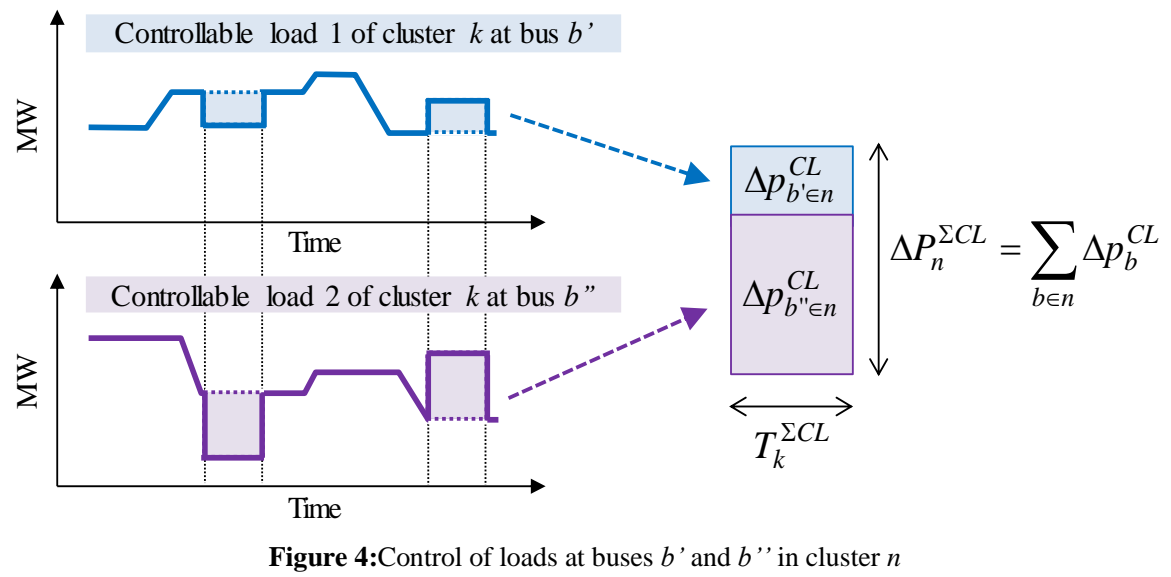

\section{3) Total bus power balance}

The power balance at each bus is computed according to (20) as the difference between both centralized and distributed generation at bus ad its instantaneous load $\left(P_{b, t}^{L}\right)$. Note that incidence matrices are needed to map the DG assets in the grid and test different configuration. Also the equality between constraints (13) and (20) allow to compute a Lagrangian that directly aggregates energy, congestion and loss costs (carbon costs here) where other approximation of the losses would require additional post processing. The MILP formulation of that optimal management (denoted OM) is finally written using YALMIP toolkit [35] and solved with CPLEX 12.7.1 (16 threads in parallel, 16 GB RAM, 3.2 GHz processor).

$P_{b, t}^{\Sigma}=P_{b, t}^{C G}-P_{b, t}^{L}+P_{b, t}^{P V}-P_{b, t}^{P V-}-P_{b, t}^{S T-}+P_{b, t}^{S T+}+\Delta p_{b \in n}^{C L} \times\left(u_{n, t}^{C L+}-u_{n, t}^{C L-}\right)+P_{b, t}^{D U}$

\section{Grid Clustering And Reduced Computational Time with Zonal ApProach}

\section{A. Computational Time Reduction}

Preliminary runs of the OM converged for different configurations of the DG assets in the considered system. However, in some cases the computational time exceeded the arbitrary limit set to 5 minutes. If a couple of minutes/hours computation would not be an issue for a day ahead scheduling problem they can become prohibitive if the OM has to be run successively a great number of times as it is the case in the DG planning iterative strategy chosen here (i.e. hundreds/thousands runs). A grid clustering approach is then considered in this section in order to furtherly reduce the computational time of the implemented OM. As already mentioned in the introduction, such clustering methods are often used to reduce the amount of input information while reducing a whole year to a sample of representative time step. Other approaches consist in aggregating the generation unit of same type or displaying close characteristics. In this paper, the clustering lies in a network partitioning (bus clustering) and the considered power system is disaggregated in smaller microgrids. The previously developed OM can then be run faster in 
each of those microgrids with a reduced numbers of variables while additional operations should ensure to maintain boundary conditions at the points of connection between the clusters.

\section{B. Electrical Network Partitioning}

The clustering method applied to the Jurong Island power system consists in a regular K-means algorithm [36] hybridized with a standard genetic algorithm similarly to [37]. The first step of the network partitioning is to define the way to compute the "electrical" distance between the buses. A typical approach consists in considering the line impedance with the bus impedance matrix $\mathbf{Z}^{\text {bus }}$. A modification is introduced in order to encourage the buses to be aggregated accordingly to their voltage level if the pre-defined number of clusters is high enough. A penalty coefficient $\lambda$ (set to $10^{3}$ ) is considered and the distance $d_{b} b^{\prime}$ " between two buses $b^{\prime}$ and $b^{\prime \prime}$ is finally computed following (21) if there is an existing branch between the buses. With highly sparse matrices for radial systems the cluster connectedness might not ensure when running a typical K-means [38]. Thus the distance between two buses $b^{\prime}$ and $b^{\prime \prime}$ with no direct link (i.e. connection line/transformer) needs to be modified. The shortest path in terms of impedance is then considered using Dijkstra's algorithm. That formulation leads to a distance matrix with no null coefficients. The cluster connectedness is automatically guaranteed as the distance computation with the Dijkstra's algorithm lies on the summation of serial impedances.

$\left\{\begin{array}{l}d_{b^{\prime} b^{\prime \prime}}=\mathbf{Z}_{\mathbf{b}^{\prime} \mathbf{b}^{\prime \prime}}^{\text {bus }} \text { if } V_{b^{\prime}}=V_{b^{\prime \prime}} \\ d_{b^{\prime} b^{\prime \prime}}=\lambda \times \mathbf{Z}_{\mathbf{b}^{\prime} \mathbf{b}^{\prime \prime}}^{\text {bus }} \text { if } V_{b^{\prime}} \neq V_{b^{\prime \prime}}\end{array}\right.$

The idea of the hybridized K-means is to use the genetic algorithm to generate different sets of clusters centers (i.e. $n$ buses defined as centers clusters $K_{n}$ ). Regular K-mean clustering is then performed for each set of centers before estimating the clustering performances which is computed as the aggregation of two indexes $((22))$. On one hand the clustering tightness index (CTI in $[0,1])$ measures the extent to which each bus is proximate to the other members in the same cluster Then the cluster size index (CSI in $[0,1])$ tends to estimate the homogeneity of the clusters with $s_{n}$ the size of the cluster containing bus $b$ and \# the cardinal function. Those two indices are gathered into a single objective $K_{o b j}$ with weights $\alpha=2$ and $\beta=1$ here. As displayed in Figure 5 the use of the genetic algorithm allow obtaining good performances with all the indexes close to unity for ten clusters or more.

$C T I=1-\frac{\sum_{b^{\prime} \in B b^{\prime \prime} \in K_{n}} d_{b^{\prime} b^{\prime \prime}}}{\sum_{b^{\prime} \in B b^{\prime \prime} \in B} \sum_{b^{\prime} b^{\prime \prime}} d}, C S I=e^{-\left(\ln \frac{\#(B)}{n}-\ln \sum_{b \in B} \frac{s_{n}}{\#(B)}\right)^{2}}, \quad K_{o b j}=C T I^{\alpha} \times C S I^{\beta}$ 

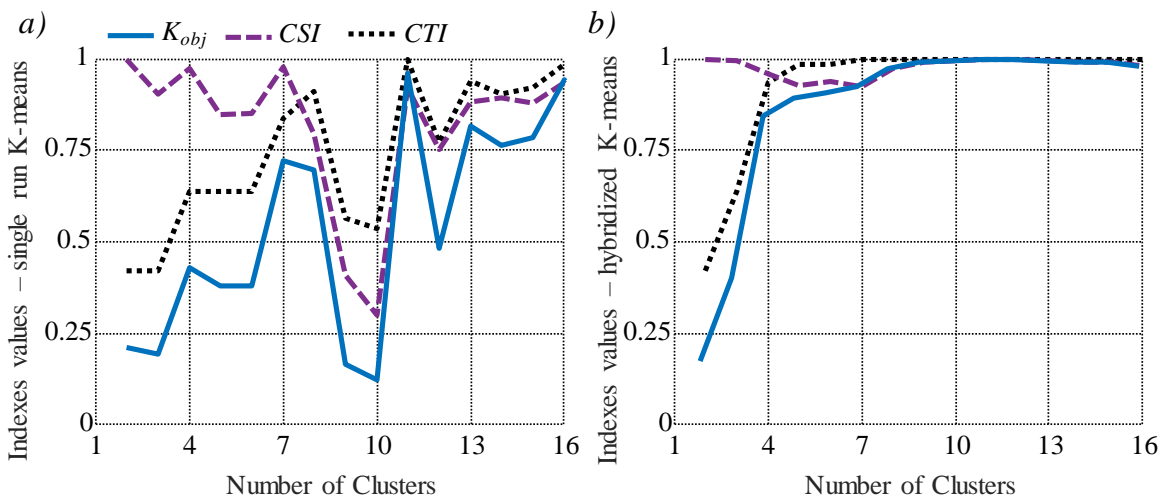

Figure 5: Clustering results $-a$ ) one run of K-means $-b$ ) hybridized K-mean $-c$ ) partitioning for 10 clusters

\section{Modified Optimal Management}

Figure $6 a$ shows the results for a grid partitioning with ten clusters $n$ each of them containing buses $b$ and lines $l$ that are subsets of the original $B$ and $L-$ denoted $b \in n$ and $l \in n$. Once the network partitioning is done, the overall system can be modeled using a zonal representation where each cluster is identified with an equivalent bus $b_{n} \in B_{n}$ and the different buses are connected thgouth lines $l_{n} \in L_{n}$ that are a subset of $L$ (Figure 6b). The zonal representation obviously corresponds to a much simpler system with a 208 buses / 210 branch system being reduced to a 10 buses / 10 branch model. Then that subsection describes a 3 steps method in order to take advantages of the zonal representation to lower the computation time of the OM when different configurations of DG assets are investigated.

a)

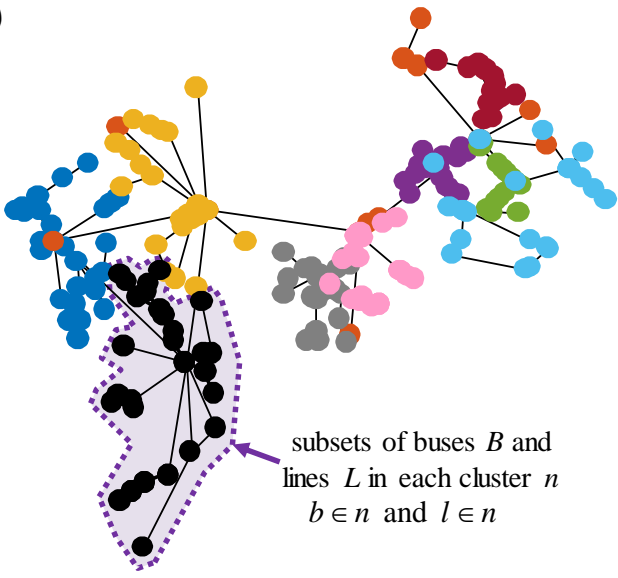

b)

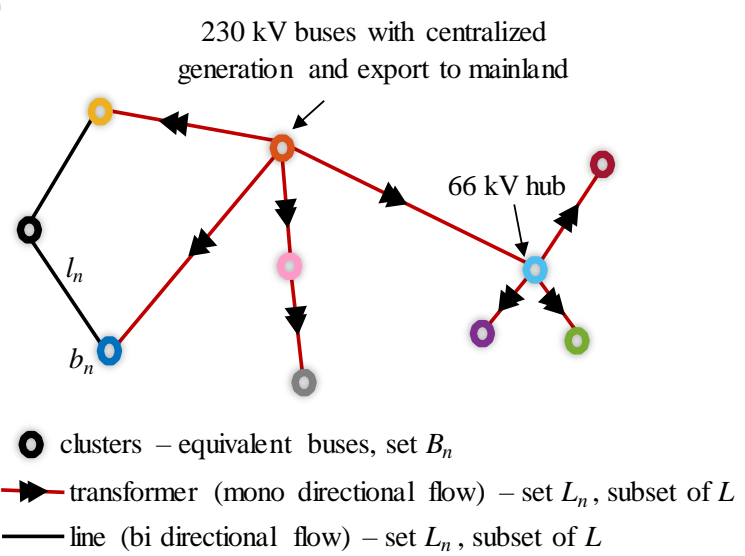

Figure 6: Network partitioning for $N=10$ clusters $-a$ ) nodal representation $-b$ ) zonal representation

\section{1) Step 1: Optimal management over the zonal modelConventional DG assets}

The first step consists in running the OM method previoulsy describe for the zonal representation of the model. The mathematical formulation does not need to be modified, excpet that the original buses and branches sets $(B$ and $L)$ have to be 
subsittued with $B_{n}$ and $L_{n}$ in the equations. However, a modification of some of the input paramters is required in order to aggregate the load, the PV generation as well as the rated power/capacity for the storage systems and ditributed CCGT units following (23). Thus each of those resources will be represented by a single equivalent asset at every bus $b_{n}$. Nota that the centralized units on site are not aggregated and, as previously, control variables will be considered for each of them. Also the controllable loads were defined to be aggregated in clusters. Thus the power magnitude of the control phase at each equivalent bus $b_{n}$ corresponds to the cluster predefined control level $\Delta P_{n}^{\Sigma C L}$. Finally, the power balance constraint at each bus (20) can be rewritten as in (24) for better understanding.

$$
\begin{aligned}
& \left\{\begin{array}{l}
P_{b_{n}, t}^{L}=\sum_{b \in n} P_{b, t}^{L} \\
P_{b_{n}, t}^{P V}=\sum_{b \in n} P_{b, t}^{P V} \\
P_{b_{n}}^{S T \max }=\sum_{b \in n} P_{b}^{S T \max } \text { and } E_{b_{n}, t}^{S T \max }=\sum_{b \in n} E_{b}^{S T m a x} \\
P_{b_{n}}^{\text {DUmin }}=\min _{b \in n}\left(P_{b}^{D U m i n}\right) \quad \text { and } \quad P_{b_{n}}^{\text {DUmax }}=\sum_{b \in n} P_{b}^{D U m a x} \\
P_{b_{n}, t}^{\Sigma}=\sum_{b \in n} P_{b, t}^{C G}-P_{b_{n}, t}^{L}+P_{b_{n}, t}^{P V}-P_{b_{n}, t}^{P V-}-P_{b_{n}, t}^{S T-}+P_{b_{n}, t}^{S T+}+\Delta P_{n}^{\Sigma C L} \times\left(u_{n, t}^{C L+}-u_{n, t}^{C L-}\right)+P_{b_{n}, t}^{D U}
\end{array}\right.
\end{aligned}
$$

The OM run for the defined zonal model is much faster that for the nodal representation of the whole system with many less variables. That number of variables in the OM is never fixed and depensd on the considered DG configuraton the number of distributed assets for each ressrouces. The ouputs of that first step are the control variables for the centralized and aggregated

DG assets as well as the power flows in lines $L_{n}$. Those flows time profiles denoted $F_{l_{n}, t}^{+*}$ and $F_{l_{n}, t}^{-*}$ define the energy exhange (i.e. import/export) between the cluster (i.e. theequivalent buses bn). However the obtained results for the zonal model would diverge from the ones computed for the complete system as losses and congestion issues within each cluster are not considered.

\section{2) Step 2 : Optimal management within each cluster}

A second step in implemented in order to refine the results inside every cluster with the OM run successively for each of them. Once again the mathematical formulation of the optimization problem does not require major modifications. The same equations are considered with subsets of $B$ and $L$ conrresponding to every cluster (i.e. considering $b \in n$ and $l \in n$ ). The DG assets are not aggregated and their nodal position and individual control variables are considered when computing the power balance constraint at each bus. However, the bus injection constrainst (13) with the line import/export is modified when considering the buses $b \in n$ that have a direct connection line with another cluster $\left(L_{n}\right)$. The equation is modified following (25) in order to ensure that the cluster $n$ export the amount of energy predicted by the previous steps with the power flows profiles 
$F_{l_{n}, t}^{+*}$ (for $l_{n}$ leaving cluster $n$ ) and $F_{l_{n}, t}^{-*}$ (for $l_{n}$ arriving at cluster $n$ ). On the contrary, imported flows $F_{l_{n}, t}^{+}$(for $l_{n}$ arriving cluster $n$ ) and $F_{l_{n}, t}^{-}$(for $l_{n}$ leaving cluster $n$ ) remain free variables subject to constraint (26) in order to ensure the convergence of the OM while compensating clusters losses or any deficit of local generation. A term is also added to the objtective function of the OML with a penalty coefficient $\lambda$ (typically $\lambda=10^{6}$ ) to keep the import of energy from the other cluster as low as possible and encourage the local generation (for both centralized and decentralized assets) ((27)).

$$
P_{b \in n, t}^{\Sigma}=\sum_{\substack{l \in \mathrm{n} \\ \text { from } \\ b \in n}}\left(F_{l, t}^{+}+\frac{\delta F_{l, t}^{+}}{2}\right)-\left(F_{l, t}^{-}-\frac{\delta F_{l, t}^{-}}{2}\right)-\sum_{\substack{l \in \mathrm{n} \\ \text { to } \\ b \in n}}\left(P_{l, t}^{+}-\frac{\delta F_{l, t}^{+}}{2}\right)-\left(P_{l, t}^{-}+\frac{\delta F_{l, t}^{-}}{2}\right)+\sum_{\substack{l_{n} \text { from } \\ b \in n}}\left(F_{l_{n}, t}^{+*}-F_{l_{n}, t}^{-}\right)-\sum_{\substack{l_{n} \text { to } \\ b \in n}}\left(F_{l_{n}, t}^{+}-F_{l_{n}, t}^{-*}\right)
$$

$\left\{F_{l_{n}, t}^{-} \geq F_{l_{n}, t}^{-*}\right.$ for lines leaving cluster $n$

$F_{l_{n}, t}^{+} \geq F_{l_{n}, t}^{+*}$ for lines arriving at cluster $n$

$o b j \leftarrow o b j+\lambda \times \sum_{t}\left(\sum_{\substack{l_{n} \text { from } \\ b \in n}} P_{l, t}^{-}+\sum_{\substack{l_{n} \text { to } \\ b \in n}} P_{l, t}^{+}\right)$

Once the second step is performed, the net load for each cluster $n\left(P_{b_{n}, t}^{N e t}\right)$ can be computed considering the load and optimal generation profiles at each buses $(b \in n)$ as well as the losses computed over the cluster lines $((28))$.

$P_{b_{n}, t}^{N e t}=\sum_{b \in n} P_{b, t}^{L}-\sum_{b \in n} P_{b, t}^{C G}-P_{b_{n}, t}^{P V}+P_{b_{n}, t}^{P V-}+P_{b_{n}, t}^{S T-}-P_{b_{n}, t}^{S T+}-\Delta p_{b}^{C L} \times\left(u_{n, t}^{C L+}-u_{n, t}^{C L-}\right)-P_{b, t}^{D U}+\sum_{l \in n} \sum_{w \in W} \alpha_{w, l}^{\delta F} \times\left(f_{w, l, t}^{+}+f_{w, l, t}^{-}\right)$

\section{3) Step 3 : Optimal management within each cluster}

A final $\mathrm{OM}$ is run for the zonal representation while considering the net load profiles for the clusters (buses $b_{n}$ ). the power balance constraint at each bus (20) is modified folllwong (29). No DG assets are considered in this step as their operation is already imlied in the computation of the cluster net load. That last runs aims at balancing the system losses and the cluster import/export with the centralized CCGT units. The sequential optimal managemet strategy is denoted as S-OM and is summarize in Figure 7.

$P_{b_{n}, t}^{\Sigma}=\sum_{b \in n} P_{b, t}^{C G}-P_{b_{n}, t}^{N e t}$ 


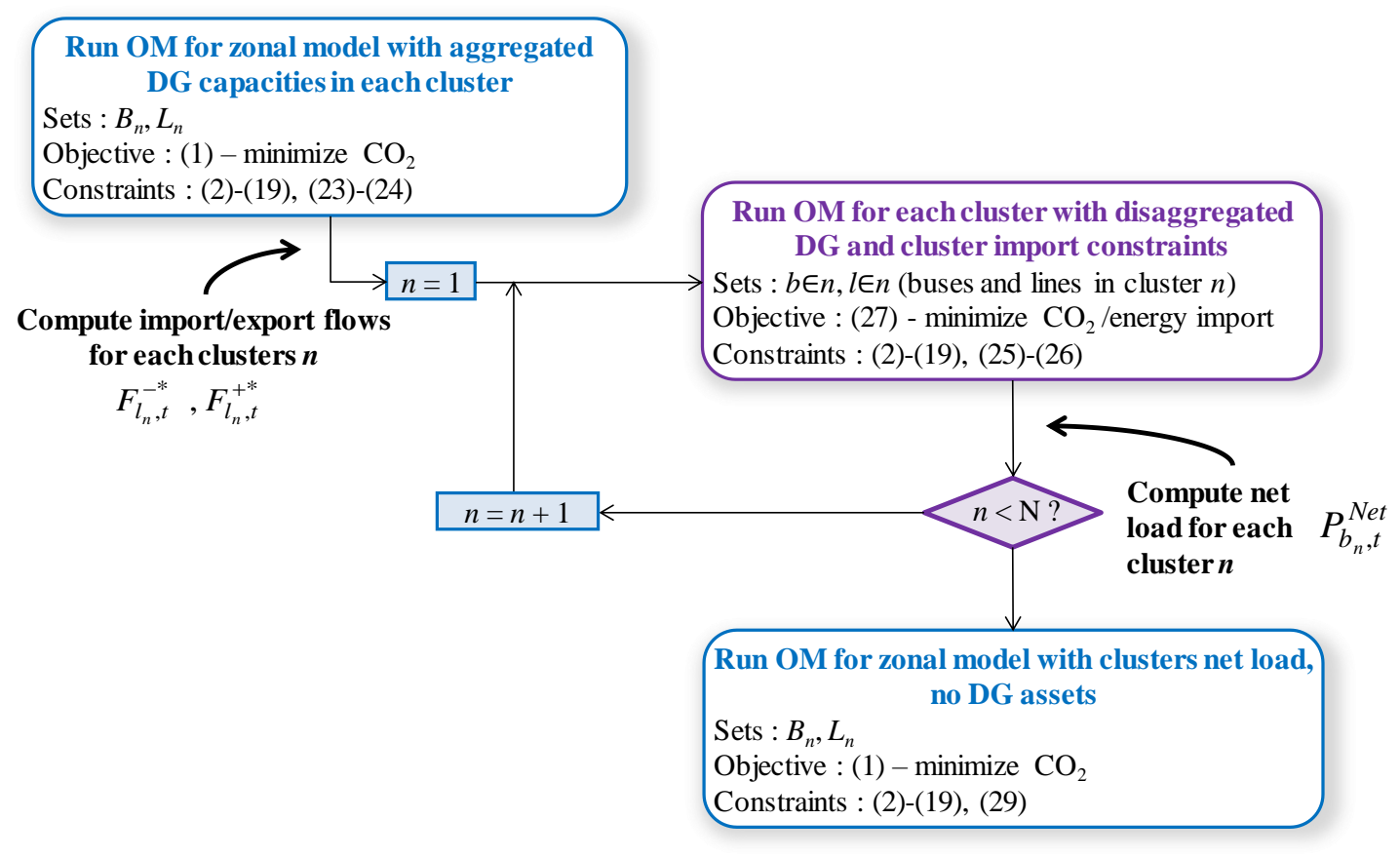

Figure 7: Architecture of the sequential optimal management (S-OM)

\section{VALIDATION RUNS ANS SAMPLE RESUltS}

\section{A. Power Plant operations}

In this section 4, validation tests for the implemented methods (OM and S-OM) are presented along with preliminary results for different DG configurations. Note the DG planning procedure is not in the scope of that paper. Thus the DG configurations that will be considered are not optimal and are only use to estimate the sensitivity of the objective function for different scenarios. The first set of simulations is run with no DG assets connected to the system. The objective is to verify the validity of the constraints in Section 2.C. that ensure appropriate operations of centralized power plants displaying several units of the same type. Figure 8 shows the results for the generation of the Sembcorp power plant with its two units of type $D$ when the constraints are inactive (Figure 8a) and activate (Figure 8b). As expected, the introduction of the power plant constraints allows to smooth the generating profiles while the value objective function remains unchanged (i.e. tons of $\mathrm{CO}_{2}$ ). Note that the overall power plant generation is consistent with for the greatest part of the day. The differences observed for the last two time steps are compensated by the same type of units in another power plant. Also note that the avoidance of multiple ripples in the units' power profile could have been done with the introduction of ramping cost that are not considered here. 

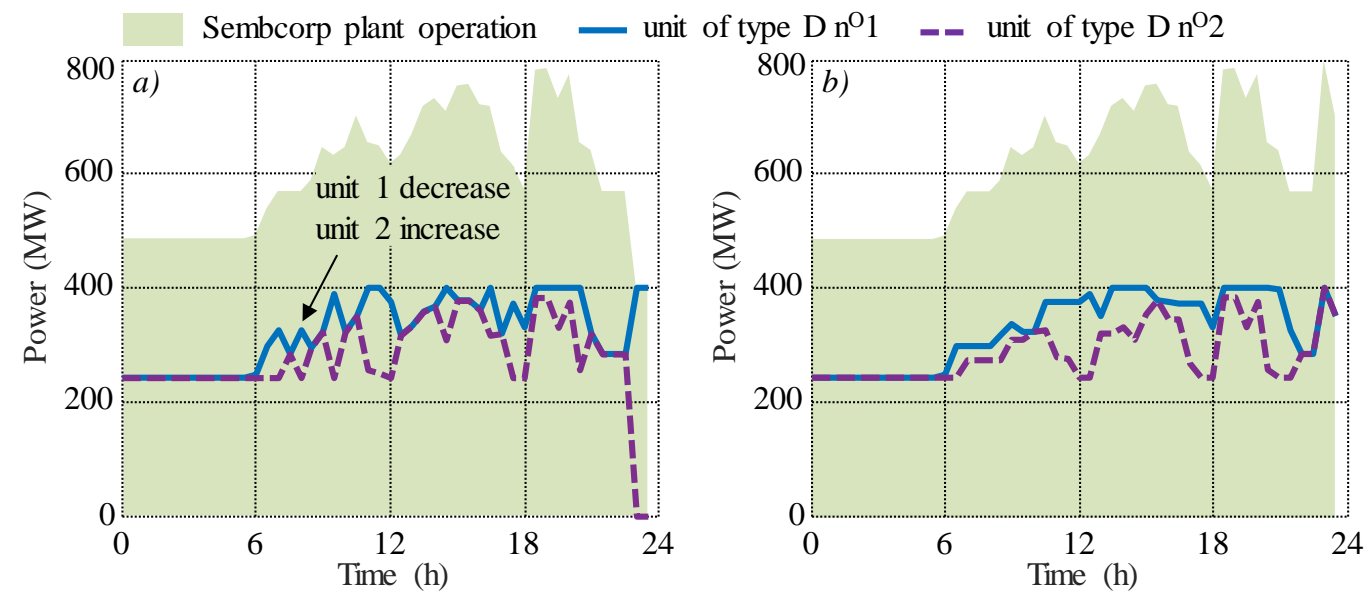

Figure 8: Sembcorp plant operation $-a$ ) inactive constraints $-b$ ) active constraints

\section{B. Line Losses}

Another set of simulations aims at validating the estimation of the line losses compared to an iterative reference method (Jump and Shift method here [23]). Serval runs of the OM wit 1 block $(W=1)$ and 2 block $(W=2)$ are performed for the Jurong Island systems as well as for the IEEE 30-bus and 57-bus test cases. As previously, those test run do not consider any DG connected to the system. Also the possibility to "correct" the ouputs of the OM is considered with a sequential AC OFP. Like for the Jump \& Shift method, those OPF are run for every time step while updating the bounds for the units generation around the power profiles returned by the OM (a tolerance of $5 \%$ is considered here). Table 2 displays the obtained results computational times are reduced using the $\mathrm{OM}$ with linearized losses. The error in the objective function (i.e. $\mathrm{CO}_{2}$ emissions) is very low, under $0.5 \%$, while the active losses difference is around $5 \%$. Running a sequential AC OPF after the OM (with $W=2$ ) allows adjusting the results and the obtained solution is even slightly better than the one returned by the Jump and Shift method.

Table 2 : Obtained Results for Jurong Island System

\begin{tabular}{|c|c|c|c|c|}
\hline & $\begin{array}{l}\text { Jump } \\
\text { Shift } \\
\end{array}$ & $\mathrm{OM}(\mathrm{W}=1)$ & $\mathrm{OM}(\mathrm{W}=2)$ & $\begin{array}{r}\mathrm{OM}(\mathrm{W}=2) \\
+\mathrm{AC} \mathrm{OPF} \\
\end{array}$ \\
\hline \multicolumn{5}{|c|}{ Jurong Island Power System - 13 units } \\
\hline Tons of $\mathrm{CO}_{2}$ & 26119 & 26116 & 26114 & 26118 \\
\hline Losses (MWh) & 219 & 211 & 206 & 219 \\
\hline CPU Time (sec) & 63 & 6 & 8 & 13 \\
\hline \multicolumn{5}{|c|}{ IEEE 30 buses - 6 units } \\
\hline Tons of $\mathrm{CO}_{2}$ & 1701 & 1681 & 1698 & 1699 \\
\hline Losses (MWh) & 59 & 36 & 52 & 55 \\
\hline CPU Time (sec) & 38 & 3 & 7 & 10 \\
\hline \multicolumn{5}{|c|}{ IEEE 57 buses - 7 units } \\
\hline Tons of $\mathrm{CO}_{2}$ & 11136 & 11036 & 11113 & 11132 \\
\hline Losses (MWh) & 309 & 275 & 286 & 300 \\
\hline CPU Time (sec) & 51 & 9 & 23 & 28 \\
\hline
\end{tabular}


The simulations also allow the analysis of the power flowing through the lines along the day for the different systems. Results for the IEEE 30-bus test case in Figure 9 show consistent power flows in the branches computed with the OM ( $W=2$ ) before and after the application of a sequential AC OPF (Figure 9a) (MW for UCLL 2 and MWA after AC OPF). Greater differences are observed when considering active losses with deviations either positive or negative (Figure 9b). However, it is noticeable that the rank of the least efficient branches is fully respected which is important when allocation problems are investigated. Indeed, the UCLL will prove able to properly discriminate two configurations (in terms of losses) where the same DG unit is connected to two different buses.

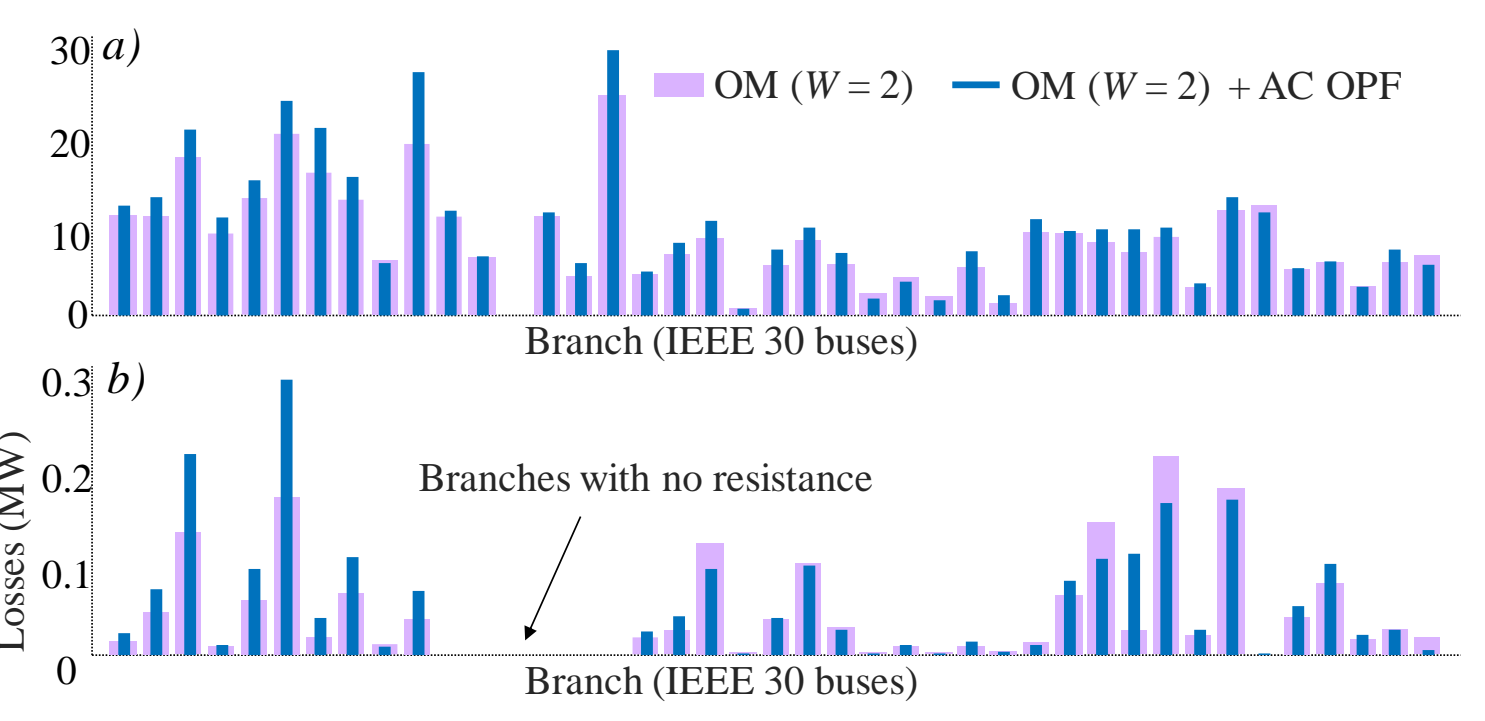

Figure 9: IEEE 30-bus results-a) line power $-b$ ) line losses

\section{Computatinal Times}

The next validation tests investigate the computational times for different DG configuration while comparing the performance of the firstly developed $\mathrm{ON}$ and the sequential version (S-OM). At first, twenty random distributions of PV installations and distributed CCGT units (DU) are tested with different capacities and allocations. The results displayed in Figure $10 a$ show good consistency while computing the emissions with the two optimization procedures. The recorded computational times are similar. The S-OM is slightly faster while the regular OML encounters one case where the arbitrary 5 minutes limit of time is reached. The OM also exceeds the time limit for one case when distributed storage is added to the investigated DG configurations. With the introduction of storage assets, the S-OM tends to be slower than the OM (when the convergence is reached) while the results in terms of emissions are still consistent (Figure 10b). When controllable loads are considered with PV and DU the emissions computed with the two methods display greater deviations. Especially the rank of the "cleanest" DG distribution is not fully 
respected any more (Figure 10c). However, the regular OM reaches the maximum computational time in most of the cases and the associated results might be sub optimal. The $\mathrm{S}-\mathrm{OM}$ overcomes that difficulty, allowing a faster convergence with lower $\mathrm{CO}_{2}$ emissions in most cases.

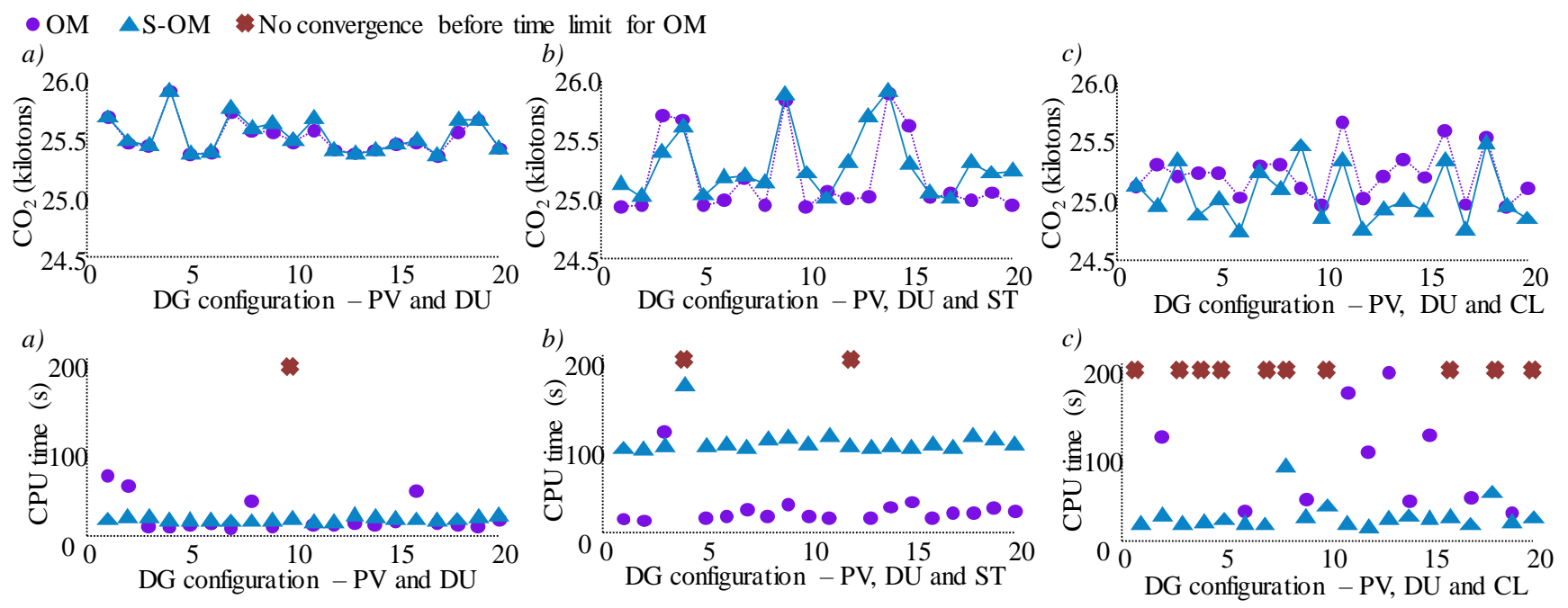

Figure 10: Comparison between $\mathrm{OM}$ and $\mathrm{S}-\mathrm{OM}-a$ ) $\mathrm{PV}$ and $\mathrm{DU}-b) \mathrm{PV}, \mathrm{DU}$ and $\mathrm{BAT}-c) \mathrm{PV}, \mathrm{DU}$ and CL.

\section{DG configurations}

\section{1) Base Case Scenario}

The last set of simulation focuses on the performances of different DG configuration regarding the objective of CO2 reduction compared to a base case scenario in which only the centralized generation on site is considered while running the OM (with $W=2$ here). As already displayed in Table 2, the simulated day corresponds to 26116 tons of $\mathrm{CO}_{2}$ emitted, with an equivalent grid emission factor of $413 \mathrm{~kg} / \mathrm{MWh}$. That value is close to the official $431 \mathrm{~kg} / \mathrm{MWh}$ estimated by the Singaporean energy authority for the year 2015 [2]. The difference can be explained by the $5 \%$ of energy generated from old, dirtier oil power plants in Singapore, which is included in the official statistics. Regarding the plant generation the bulk load is provide by the cleanest units (type A in Keppel and type C in Seraya) while the dirtier generator are started up to supply the peak demand (Figure $11 b$ ). The system displays very low losses equals to $0.35 \%$ when computed over the entire day (Figure $11 a$ ). Note that only higher voltage lines are considered here. The total grid losses (transmission/distribution) in Singapore is estimated around $2 \%$ according to the International Energy Agency. Those low values are explained by the low impedance underground cables on site as well as by the short distances between the nodes. 

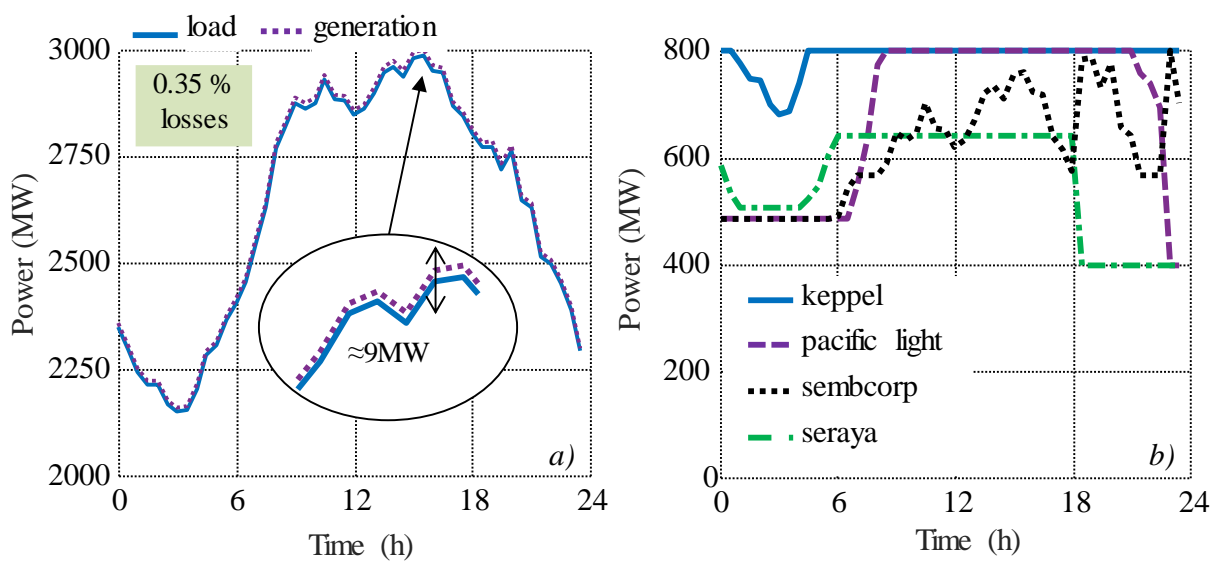

Figure 11: Power profiles for the base case scenario-a) load and generation $-b$ ) plants operation

\section{2) Conection of DG assets on a test feeder}

A firs set of simulations is performed considering the 20 MVA rated feeder connecting the buses 165-168 (Figure 2a). Once again, the tests do not imply any optimal DG size/site. Here the idea is to validate the problem formulation for an arbitrary chosen feeder. Different DG resources are successively connected to the nodes and results are estimated regarding the overall $\mathrm{CO}_{2}$ emissions and losses reduction within the feeder. For the base case (S0) the feeder is loaded according to the buses consumption profiles along the day for a total of 4.3 MWh losses. Then a scenario (S1) is simulated with the connection of a 30 MWc PV plant to node 168 . That peak power is at an arbitrary high value (greater that the feeder capacity which is not realistic) in order to validate the generation curtailment in case of important surplus of production. In practice, most of the generation is self-consumed by the local loads and the surplus flows upstream to the main grid (Figure 12a). Losses within the feeder are significantly reduced (more than $25 \%$ ) as a result of the shortened distance between the generation and the load point (Table 3). Adding a $1 \mathrm{MW} / 5 \mathrm{MWh}$ storage to the same bus (S2) does not improve the performance much with a net load slightly reduced during short periods (Figure 12a). A cluster of controllable loads is then considered (S3) with 1MW shifted at nodes 165, 166 and 167 for 3 hours (Figure 12b). As expected the load is increased when the PV peak occurs. It leads to less energy exported to the grid, which corresponds to reduced losses in the feeder. Once again the benefits are not significant and many more loads should be controlled to get a real impact on $\mathrm{CO}_{2}$ reduction. A last simulation is performed with the addition of a $5 \mathrm{MW}$ distributed CCGT unit at bus 165 (S4). The optimal profiles returned by the OM method logically correspond to full-time operation of the distributed clean CCGT unit (Figure 12b) to lower the overall emissions.

Table 3 : DG connected to the tested branch

\begin{tabular}{llllll}
\hline & S0 & S1 & S2 & S3 & S4 \\
\hline $\mathrm{CO}_{2}$ (tons) & 26114 & 26056 & 26055 & 26054 & 26029 \\
Losses $(\mathrm{MWh})$ & 4.3 & 3.0 & 2.9 & 2.7 & 1.8 \\
\hline
\end{tabular}



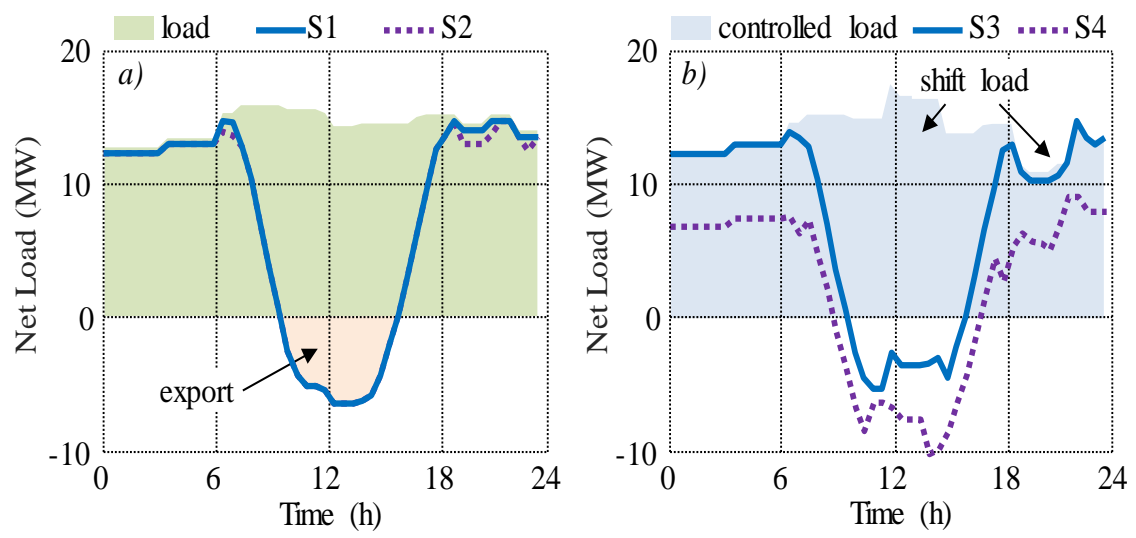

Figure 12: Feeder load $-a$ ) S0, S1 and $\mathrm{S} 2-b$ ) S3 and S4

\section{3) Impact of DG size and site}

Additional simulations are run with increasing DG capacities. For each type of DG resources, the installed capacity is distributed among five arbitrary buses (Figure $2 a$ ). Storage units are given with a power/energy ratio equal to one and a single cluster aggregates the load controlled at the test buses. As previously observed, photovoltaic and distributed CCGT units have the most significant impact on the carbon cost, with reduced system losses (Figure 13a). Both emissions and losses tend to decrease linearly as more capacity is installed. There is no major improvement when only controllable loads or energy storage are considered, even with greater capacities involved. Indeed, those two resources only allow shifting consumption through time and they cannot directly contribute to carbon reduction by themselves when a given amount of energy has to be consumed along the day. However, a slight improvement is observed with capacities above $15 \mathrm{MW}$. In those cases, the resources provide enough flexibility to allow a small benefit from the arbitrage between dirtier and cleaner CCGT centralized units. Typically, generation from the cleanest units is increased at night time and the reduced consumption during the day allows minimizing the time period where dirtier technologies are committed. The gain in terms of tons of $\mathrm{CO}_{2}$ is then directly linked to the carbon cost difference between the different type of units. With only one type of fuel considered here (i.e. natural gas) the costs are very close to each other, which explains the almost non observable improvement. Note that the efficiency attached to storage units lead to increased losses even if the overall carbon cost is lower than in the base case scenario (Figure 13b). The DG resource siting is then investigated by distributing a same amount of DG capacity (30 MW) among different nodes. Twenty random sets of buses considered - sets of one, three, five and ten buses. As previously observed the carbon emissions decrease proportionally to losses when PV units are investigated (Figure 14a). However, the PV siting does not have any impact on the system performance, with a variation less than a ton (i.e. $<0.01 \%$ ) over the twenty simulated scenarios. It becomes a little more significant when allocation 
of decentralized CCGT units is studied. In particular, distributing the capacity among several buses seems to correspond to slightly improved performance (around $1 \%$ ) (Figure 14b).
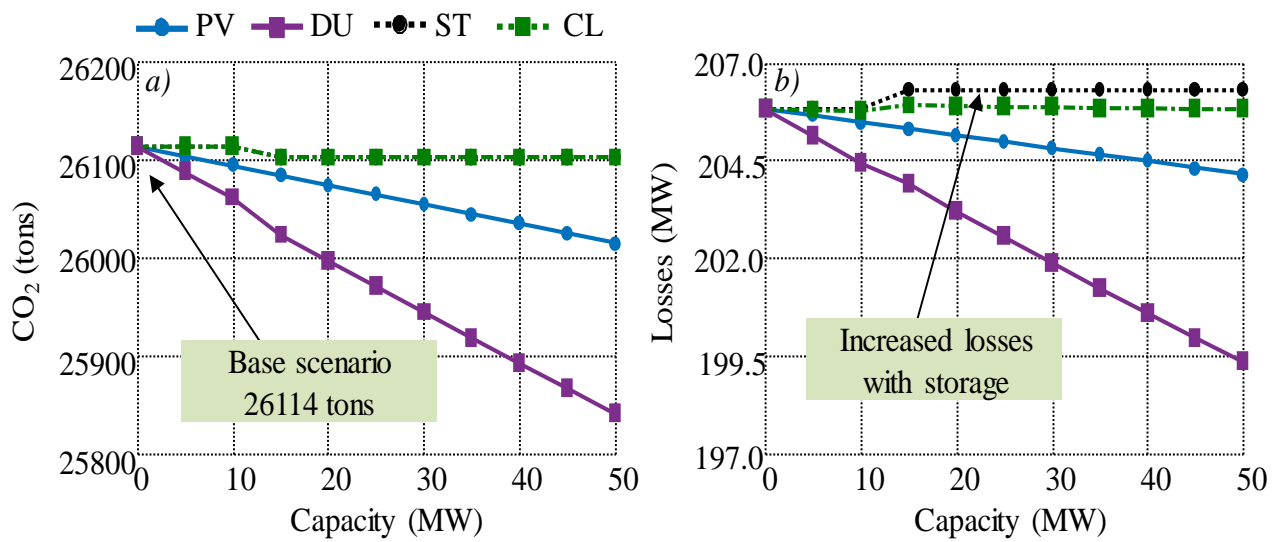

Figure 13: Impact of DG size at 5 arbitrary test buses-a) $\mathrm{CO}_{2}$ emissions for different capacities $-b$ ) losses for different capacities
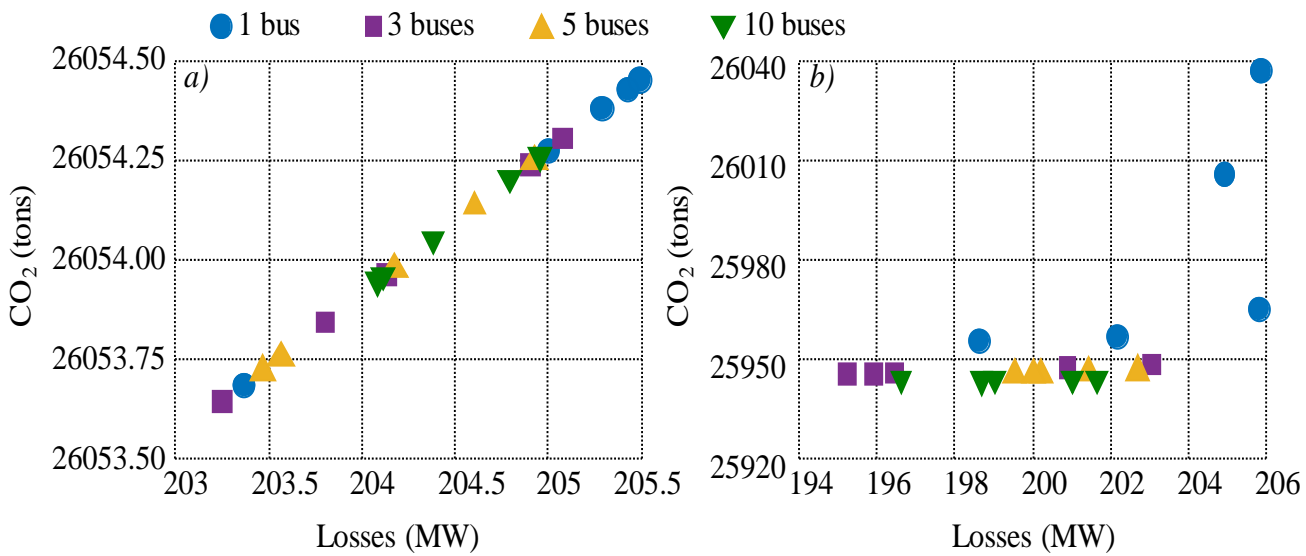

Figure 14: Impact of DG sites-a) different PV locations $-b$ ) different DU locations

A last set of simulations is performed with different sizes/sites considering only the distributed phtotovoltaic and storage devices. Different number of units of $10 \mathrm{MWp}$ (for PV) and $10 \mathrm{MWh}$ (for ST) are randomly distributed among the Jurong Island system in order to reach the total distributed capacities (denoted $\mathbf{S} \mathbf{T}_{\text {tot }}$ and $\mathbf{P V}$ tot). Note that the considered capacities are unrealistic regarding the available space on Jurong Island and that those simulations should be considered as a partial sensitivity analysis. As already noticed in the previous simulations the improvements in terms of $\mathrm{CO}_{2}$ reduction are not significant. Indeed the results displayed in Table 4 show around $1 \%$ reduction for every $100 \mathrm{MWp}$ of PV installed - which is in the range of the total installed capacity currently installed in the whole Singapore. The impact of the storage is even more limited less than $0.5 \%$ reduction for $500 \mathrm{MWh}$ ! The results are the same when storage units are connected at the same buses as the PV plant and with the same capacities $\left(\mathbf{P V}\right.$ tot $=\mathbf{S} \mathbf{T}_{\text {tot }}$ in Table 4$)$. 
Table 4 : $\mathrm{CO}_{2}$ emisiosn for fdiffenrt PV and ST configurations

\begin{tabular}{c|cccccc}
\hline PV $_{\text {tot }}$ ST $_{\text {tot }}$ & 0 MWh & 100 MWh & 200 MWh & 300 MWh & 400 MWh & 500 MWh \\
\hline 0 MWp & 26114 & 26070 & 26042 & 26031 & 26030 & 26023 \\
$\mathbf{1 0 0} \mathbf{M W p}$ & 25914 & 25869 & 25830 & 25818 & 25640 & 25545 \\
$\mathbf{2 0 0} \mathbf{M W p}$ & 25704 & 25645 & 25251 & 25250 & 25251 & 25251 \\
$\mathbf{3 0 0} \mathbf{M W p}$ & 25503 & 25065 & 25049 & 25063 & 25048 & 25041 \\
$\mathbf{4 0 0} \mathbf{M W p}$ & 25073 & 24866 & 24848 & 24848 & 24847 & 24841 \\
$\mathbf{5 0 0}$ MWp & 24720 & 24698 & 24648 & 24649 & 24648 & 24640 \\
\hline PV $_{\text {tot }=\text { ST }}$ & 26114 & 25870 & 25250 & 25048 & 24848 & 24640 \\
\hline
\end{tabular}

Those low improvements are explained by the nature of the considered Jurong Island power system. Especially, there is no energy mix regarding the centralized generation with all the CCGT units fueled with natural gas. As displayed on Figure $2 b$ the performances of the units in terms of $\mathrm{CO}_{2}$ emissions are close. Thus if DG allow reducing the generation of the "dirtiest" unit, improvement will not be significant. Also the rated power of the centralized unit (around 400MW each) is high regarding the load level (3GW). It means that important levels of DG should be installed in order to cover the contribution of a single unit and avoid starting it which might be unrealistic as observed in Table 4 . The uselessness of storage device can be more specifically explained with the optimal scheduling problem that does not consider any time varying parameters (e.g. time of use or real time prices). The objective function is only the amount of $\mathrm{CO}_{2}$ for the power generation and the interest of using storages to perform arbitrage thought time is limited here. The main contribution of storage unit would be to shave the overall peak demand in order to reduce the generation of the "dirtier" unit. However, once again the absence of energy mix with similar generator limit the expected improvements in terms of $\mathrm{CO}_{2}$ savings.

\section{CONCLUSIONS}

The method developed in this paper presents an optimal energy management of a power system in the presence of different types of DG resources and with the centralized generation already installed on site. The case study refers to the Jurong Island in Singapore. A particular attention is attached to the computational time of the procedure as that management loop aims at being integrated in a DG planning method that would require to test many configurations of the DG assets. At first, the use of a modified DC OPF implemented in the form of MILP problem avoids computational complexity. Especially, the method lies in a piecewise linearization of the lines losses that has been validated over several systems (Jurong Island and IEEE test cases) and compared to another method with AC OPF constraints taken as the reference. In a second time a clusterised version of the optimal management is developed once a generic method is developed for network partitioning. Validation us showed that the clusterized method allow to reduce the computational time and the convergence before an arbitrary limit of five minutes. The implementation 
of the DG optimal planning is not in the scope of the paper. However, some simulations have been performed in order to estimate the improvement in terms of $\mathrm{CO} 2$ reduction depending on the DG types, sizes and sites. If the obtained results validated the implemented models and constraints, they did not how significant improvements compared to a bases case scenario in which only the centralized generation on site is considered. That is directly link to the nature of the Jurong Island power system with very low losses and only gas fueled units (i.e. no generation mix). Considering objective function with other parameters such as operating costs or carbon taxes might create more space for improvements. That should be part of further works should as well as the integration of the management strategy in a design procedure in order to find the best DG configuration.

\section{REFERENCES}

[1] R. Rigo-Mariani, K. V. Ling, J. Maciejowski, "A generic method to model $\mathrm{CO}_{2}$ emission Performances of combined cycle power plants for environmental unit commitment”, Energy Technology, 2017.

[2] Energy Market Authority, Singapore Energy Statistics, 2016 http://www.ema.gov.sg

[3] P. Prakash, D. K. Khatod, "Optimal sizing and siting techniques for distributed generation in distribution systems: A review", Renewable and Sustainable Energy Reviews, vol. 57, pp. 111-130, 2016.

[4] A. R. Jordehi, "Allocation of distributed generation units in electric power systems: A review", Renewable and Sustainable Energy Reviews, vol. 56, pp. 893-905, 2016.

[5] P. Paliwal, N. P. Patidar, R. K. Nema, "Planning of grid integrated distributed generators: A review of technology, objectives and techniques", Renewable and Sustainable Energy Reviews, vol. 40, pp. 557-570, 2014.

[6] N. Acharya, P. Mahat, N. Mithulananthan, "An analytical approach for DG allocation in primary distribution network", Electrical Power and Energy Systems, Vol. 28, pp. 669-678, 2006.

[7] S. Ghosh, S.P. Ghoshal, S. Ghosh, "Optimal sizing and placement of distributed generation in a network system", Electrical Power and Energy Systems, Vol. 32 pp. 849-856, 2010.

[8] M. Nayeripour, E. Mahboubi-Moghaddam, J. Aghaei, A. Azizi-Vahed, "Multi-objective placement and sizing of DGs in distribution networks ensuring transient stability using hybrid evolutionary algorithm", Renewable and Sustainable Energy Reviews, Vol. 25, pp. 759-767, 2013.

[9] R. Prenc, D. Skrlec, V. Komen, "Distributed generation allocation based on average daily load and power production curves", Electrical Power and Energy Systems, vol. 53, pp. 612-622, 2013.

[10] G. Vigano, M. Rossi, D. Moneta, C. Carlini, "Methodology for the optimal siting and sizing of storage systems in distribution networks", AEIT Internation Annual Conference, Naples, Italy, 2015.

[11] F. Abbasi, S. M. Hosseini, "Optimal DG allocation and sizing in presence of storage systems considering network configuration effects in distribution systems", IET Generation, Transmission \& Distribution, Vol. 10, No. 3, pp. 617-624, 2016.

[12] D. H. Popovic, J. A. Greatbanksb, M. Begovic, A. Pregelj, "Placement of distributed generators and reclosers for distribution network security and reliability", Electrical Power and Energy Systems, Vol. 27, pp. 398-408, 2005.

[13] T. Gozel, M. H. Hogaoglu, U. Eminoglu, A. Balikci, "Optimal Placement and Sizing of Distributed Generation on Radial Feeder with Different Static Load Models", International Conference on Future Power Systems, Amsterdam, Netherlands, 2005.

[14] M. R. Vallem, J. Mitra, "Siting and sizing of distributed generation for optimal microgrid architecture", 37th Annual North American Power Symposium, 2005.

[15] L. F. Ochoa, C. J. Dent, G. P. Harrison, "Distribution network capacity assessment: variable DG and Active networks", IEEE Trans. on Power Systems, Vol. 25, No. 1, pp. 87-95, 2010.

[16] S. Porkar, P. Poure, A. Abbaspour-Tehrani-Fard, S. Saadate, "Optimal allocation of distributed generation using a two-stage multi-objective mixedinteger-nonlinear programming", European Transactions on Electrical Power, Vol. 21, pp. 1072-1087, 2011.

[17] H. Pandžić, Y. Wang, T. Qiu, Y. Dvorkin, D. S. Kirschen, "Near-optimal method for siting and sizing of distributed storage in a transmission network", IEEE Transactions on Power Systems, vol. 25, no. 1, pp. 2288-2300, 2015.

[18] J. Stich, T. Massier, "Enhancing the integration of renewables by trans-border electricity trade in ASEAN", IEEE PES Asia-Pacific and Energy Engineering Conference, 2015.

[19] H.K. Fathy, J.A. Reyer, P.Y. papalambos et A.G Ulsoy, "On the coupling between the plant and controller optimization problems", American Control Conference, Arlington, 2001.

[20] F. Ugrandi, E. Karatepe, "Optimal wind turbine sizing to minimize energy loss", Electrical Power and Energy Systems, Vol. 53, pp. 656-663, 2013.

[21] G. Celli, S. Mocci, F. Pilo, M. Loddo, "Optimal integration of energy storage in distribution networks", IEEE Bucharest Power Tech Conference, June 28th - July 2nd, Bucharest, Romania, 2009.

[22] F. Rotaru, G. Chicco, G. Grigoras, G. Cartina, "Two-stage distributed generation optimal sizing with clustering-based node selection, "Electrical Power and Energy Systems, Vol. 40, pp. 120-129, 2012.

[23] S. X. Chen, H. B. Gooi, "Jump and shift method for multi-objective optimization", IEEE Trans. On Industrial Electronics, vol 58, no 10, pp 4538-4548, 2011.

[24] F. Li, R. Bo, "DCOPF-Based LMP Simulation: algorithm, comparison with ACOPF, and sensitivity", IEEE Transaction on Power Sytems, Vol. 22, No. 4, pp. 1475-1485, 2007.

[25] L. Zhang, T. Capuder, Member, P. Mancarella, “”, Unified unit commitment formulation and fast multi-service LP model for flexibility evaluation in sustainable power systems", IEEE Transactions in Sustainable Energy, Vol. 7, No. 2, 2016. 
[26] B. S. Palmintier, M. D. Webster, "Heterogeneous unit clustering for efficient operational flexibility modeling”, Power \& Energy Society General Meeting, National Harbor, United States, 2014.

[27] K. Van den Bergh, K. Bruninx, E. Delarue, W. D'haeseleer, "A Mixed-Integer Linear Formulation of the Unit Commitment Problem", KU Leuven, TME working paper, 2014. [Online] Available: https://www.mech.kuleuven.be/en/tme/research/energy_environment/Pdf/wpen2014-07.pdf.

[28] M. Carrión, J. M. Arroyo, "A computationally efficient mixed-integer linear formulation for the thermal unit commitment problem", IEEE Trans. On Power Systems, vol 21, no. 3, pp 1371-1378, 2006.

[29] M. P. Boyce. "Handbook for cogeneration and combined cycle power plants", ASME Press (2 ${ }^{\text {nd }}$ ed), 2010.

[30] F. Li, "Fully reference-independent LMP decomposition using reference-independent loss factors", Electrical Power Systems Research, Vol. 81, pp. 19952004

[31] H. Seifi, M. S. Sepasian, "Electric Power System Planning - Issues, Algorithms and Solutions", Springer, ISSN 16121287, New-York, 2011.

[32] http:// pvwatts.nrel.gov

[33] S. W. Alnaser, L. F. Ochoa, "Optimal sizing and control of energy storage in wind power rich distribution networks", IEEE Transactions on Power Systems, Vol. 31, No. 3, pp. 2004-2013, 2016.

[34] K. Kok, S. Widergren, "A society of devices : integrating intelligent distributed resources with transactive energy", IEEE Power and Energy Magazine, Vol. 14, No. 3, pp. 34-45, 2016.

[35] J. Lofberg, "YALMIP: a toolbox for modelling and optimization in MATLAB", IEEE International Symposium on Computer Aided Control Systems Design, New-Orleans, USA, 2004, pp. 282-289.

[36] A. K. Jain, "Data clustering: 50 years beyond K-means", Pattern Recognition Letters, vol 31, pp. 651-666, 2010.

[37] S. Blumsack, P. Hines, M. Patel C, Barrows, E. Cotilla Sanchez, "Defining power network zones from measures of electrical distances", Power \& Energy Society General Meeting, Calgary, Canada, 2009.

[38] E. Cotilla Sanchez, P. Hines, Barrows, S. Blumsack, M. Patel C, "Multi-attribute partitioning of power networks based on electrical distance", IEEE Transactions on Power Systems, vol. 28, no. 4, pp. 4979-4987, 2013.

[39] M. Nick, R. Cherkaoui, M. Paolone, "Optimal allocation of dispersed energy storage systems in active distribution networks for energy balance and grid support”, IEEE Transactions on Power Systems, Vol. 29, No. 5, pp. 2300-2310, 2014.

[40] W. El-Khattam, K. Bhattacharya,Y. Hegazy, M. M. A. Salama, "Optimal investment planning for distributed generation in a competitive electricity market”, IEEE Transactions on Power Systems, Vol. 19, No. 3, pp. 1674-1684, 2004.

[41] G. Muñoz-Delgado, J Contreras, J. M. Arroyo, "Joint expansion planning of distributed generation and distribution networks", IEEE Transactions on Power Systems, Vol. 30, No. 5, pp. 2579-2590, 2015.

[42] R. K. Singh, S. K. Goswami, "Optimum siting and sizing of distributed generations in radial and networked systems", Electric Power Components and Systems, Vol. 37, pp. 127-145, 2009.

[43] S. W. Alnaser, L. F. Ochoa, "Optimal sizing and control of energy storage in wind power rich distribution networks", IEEE Transactions on Power Systems, Vol. 31, No. 3, pp. 2004-2013, 2016.

\section{ACKNOWLEDGEMENT}

The authors acknowledge the support by the Singapore National Research Foundation under its Campus for Research

Excellence And Technological Enterprise (CREATE) programme and the Cambridge Centre for Advanced Research in Energy

Efficiency in Singapore Ltd (CARES). 
APPENDiX A COMPACT. LITTERATURE REVIEW OF DG PLANNING PROBLEMS AND SOLVING METHODS

\begin{tabular}{|c|c|c|c|c|c|}
\hline Ref & $\begin{array}{l}\text { System } \\
\text { size }\end{array}$ & $\begin{array}{l}\text { Load } \\
\text { level }\end{array}$ & Objectives & $\begin{array}{ll}\mathrm{AC} / \mathrm{DC} \\
\text { model }\end{array}$ & Method \\
\hline [11] & 33 bus & 1 snap & Bi objective - cost and losses & $\mathrm{AC}$ & $\begin{array}{l}\text { Multi objectives genetic algorithm (NSGA II) for } \\
\text { multiple DG site/size }\end{array}$ \\
\hline [9] & 30 bus & 1 day & Minimize losses & $\mathrm{AC}$ & $\begin{array}{l}\text { Integrated - Sequential AC OPF and GA for } \\
\text { multiple DG resources size/site }\end{array}$ \\
\hline [17] & 96 bus & 1 year & $\begin{array}{l}\text { Minimize capital and } \\
\text { operating cost }\end{array}$ & DC & All in one - MILP formulation for storage site/size \\
\hline [15] & 61 bus & 1 year & Maximize wind penetration & $\mathrm{AC}$ & $\begin{array}{l}\text { All in one - Sequential AC OPF with a finite set of } \\
\text { scenarios to represent a year for wind turbine size }\end{array}$ \\
\hline [6] & 69 bus & 1 snap & Minimize losses & $\mathrm{AC}$ & $\begin{array}{l}\text { Analytical function to compute the loss sensitivity } \\
\text { factor for single DG site/size }\end{array}$ \\
\hline [7] & 30 bus & 1 snap & $\begin{array}{l}\text { Weighted sum - losses and } \\
\text { cost }\end{array}$ & $\mathrm{AC}$ & Exhaustive search with ACPF for single DG site/size \\
\hline [8] & 33 bus & 1 snap & $\begin{array}{l}\text { Weighted sum - losses, } \\
\text { reliability and voltage }\end{array}$ & $\mathrm{AC}$ & $\begin{array}{l}\text { Hybrid particle swarm optimization for multiple DG } \\
\text { site/size }\end{array}$ \\
\hline [10] & 32 bus & 1 day & Minimize losses & $\mathrm{AC}$ & $\begin{array}{l}\text { Iterative - Monte Carlo simulation with multi period } \\
\text { AC OPF for storage site/size }\end{array}$ \\
\hline [20] & 30 bus & 4 days & Minimize losses & $\mathrm{AC}$ & $\begin{array}{l}\text { Integrated - Sequential AC OPF and GA for } \\
\text { multiple wind turbines size/site }\end{array}$ \\
\hline [27] & 69 bus & 1 snap & Minimize losses & $\mathrm{AC}$ & $\begin{array}{l}\text { Analytical method for single and multiple DG } \\
\text { site/size }\end{array}$ \\
\hline [22] & 24 bus & 1 day & $\begin{array}{l}\text { Weighted sum - loss and } \\
\text { voltage profile }\end{array}$ & $\mathrm{AC}$ & $\begin{array}{l}\text { Iterative - Clustering method and sequential AC } \\
\text { OPF for PV and CHP site/size }\end{array}$ \\
\hline [40] & 8 bus & 1 day & $\begin{array}{l}\text { Minimize capital and } \\
\text { operating cost }\end{array}$ & $\mathrm{AC}$ & $\begin{array}{l}\text { Heuristic approach to sort the best locations and } \\
\text { sequential AC OPF for multiple DG }\end{array}$ \\
\hline [12] & 114 bus & 3 days & $\begin{array}{l}\text { Weighted sum - losses, } \\
\text { reliability and voltage }\end{array}$ & $\mathrm{AC}$ & $\begin{array}{l}\text { Sequential AC OPF and exhaustive sear for DG } \\
\text { placement, GA for reliability }\end{array}$ \\
\hline [13] & 13 bus & 1 snap & Minimize losses & $\mathrm{AC}$ & $\begin{array}{l}\text { Exhaustive search of the optimal site mixed with } \\
\text { analytical computation of optimal size }\end{array}$ \\
\hline$[14]$ & 6 bus & 1 snap & Minimize cost & $\begin{array}{l}\mathrm{DC} \\
\text { reliability }\end{array}$ & Simulated annealing for multiple DG site/size \\
\hline [39] & 34 bus & 150 snap & $\begin{array}{l}\text { Minimize capital and } \\
\text { operating cost }\end{array}$ & $\mathrm{AC}$ & $\begin{array}{l}\text { All in one - Second order conic programming for } \\
\text { storage site/size }\end{array}$ \\
\hline [16] & 30 bus & 1 year & $\begin{array}{l}\text { Weighted multi obj - losses } \\
\text { and cost }\end{array}$ & $\mathrm{AC}$ & $\begin{array}{l}\text { All in one }- \text { Sequential AC OPF for multiple DG } \\
\text { resources size/site }\end{array}$ \\
\hline [18] & 87 bus & 6 weeks & $\begin{array}{l}\text { Minimize capital and } \\
\text { operating cost }\end{array}$ & DC & $\begin{array}{l}\text { All in one - LP formulation for multiple DG } \\
\text { resources size/site }\end{array}$ \\
\hline [41] & 138 bus & 3 snap & $\begin{array}{l}\text { Weighted sum- losses and } \\
\text { cost }\end{array}$ & DC & $\begin{array}{l}\text { MILP for both grid (feeder, substations) and DG } \\
\text { planning }\end{array}$ \\
\hline [31] & 17 bus & 1 day & $\begin{array}{l}\text { Minimize capital and } \\
\text { operating cost }\end{array}$ & DC & $\begin{array}{l}\text { Integrated - DP for management loop and GA for } \\
\text { design for storage site/size }\end{array}$ \\
\hline [42] & 30 bus & 3 snap & Minimize losses & $\mathrm{AC}$ & $\begin{array}{l}\text { Genetic algorithm for single and multiple DG } \\
\text { site/size }\end{array}$ \\
\hline [43] & 18 bus & 1 day & $\begin{array}{l}\text { Minimize renewable energy } \\
\text { curtailment }\end{array}$ & $\mathrm{AC}$ & Iterative - Multi period AC OPF for storage site/size \\
\hline This work & 208 bus & 1 day & Minimize $\mathrm{CO}_{2}$ emissions & $\begin{array}{l}\text { DC with } \\
\text { losses }\end{array}$ & $\begin{array}{l}\text { Iterative }- \text { Estimation of the impact of multiple DG } \\
\text { resources (PV, storage, DU and CL) }\end{array}$ \\
\hline
\end{tabular}


CHP : Combined Heat ANd Power, NSGA : Non-dominated Sorting GenetiC Algorithm, OPF : OPTIMAl PoWer Flow, SNAP : OMe lOAD LeVel (SNAPSHOT) 